\title{
Multiplexing in Multi-Reflecting TOF MS
}

\author{
Anatoly Verenchikov ${ }^{1, *}$, Sergey Kirillov ${ }^{1}$, Yury Khasin ${ }^{1}$, Vasily Makarov ${ }^{1}$, Mikhail Yavor ${ }^{1}$ and \\ Viatcheslav Artaev ${ }^{2}$
}

${ }^{1}$ MSC-CG, A5, JNA blv, Bar, 85000, Montenegro

${ }^{2}$ LECO Corporation, 300 Lakeview dr, St. Joseph, MI, USA

\begin{abstract}
The paper presents an overview of original inventions, development and experimental results by the group of authors in the area of multi-reflecting time-of-flight mass spectrometry with Folded Flight Path (FFP ${ }^{\circledR}$ (MR-TOFMS) with main focus on multiplexing methods for improving the analysis throughput, i.e. the amount of information per time unit. MR-TOF provides panoramic spectra (virtue of TOFMS), while significantly enhancing resolving power, thus, providing yet more information. Resolving power $\mathrm{R}=500,000$ is demonstrated to resolve isobars and to improve mass accuracy to sub-ppm level. Encoded Frequent Pulsing (EFP ${ }^{\mathrm{TM}}$ ) method improves sensitivity, expands dynamic range and opens multiple incarnations of parallel and fast tandem methods of analysis based on using ion traps, TOFMS and ion mobility for rapid and lossless parent ion separations.
\end{abstract}

Keywords: Multi-reflecting TOF, multiplexing, N-dimensional separations, high throughput.

\section{INTRODUCTION}

Mass spectrometry is a very powerful analytical technique, which rapidly becomes the core method of analytical chemistry. High throughput is a very desirable feature for mass spectrometry analysis. The amount of information per time unit is the key metric for solving complex problems within a reasonable amount of resources and time.

Time-of-flight mass spectrometers (TOFMS) is a widely used MS method, chosen for sensitivity, rapid spectral acquisition capability and, lately, for high resolution and mass accuracy. In a sense, the TOFMS method implements multiplexing on its' own: panoramic spectra of all ionic species are acquired at once (at millisecond time scale) for a single ion ejection from an ion source.

Since introduction in 1948 [1], multiple improvements were made for improving TOFMS resolution, including a method of time-lag ion extraction [2], energy focusing by electrostatic sectors [3], energy focusing and trajectory folding with grid covered mirrors $[4,5]$ and gridless mirrors [6, 7]. TOFMS have been successfully adopted for intrinsically pulsed ion sources, like SIMS [8], MALDI [9, 10], or accumulating Electron Impact (EI). Application of TOFMS has been extended to continuous ion sources, like Electrospray, $\mathrm{APCl}$ and $\mathrm{El}$, with introduction of orthogonal acceleration $(\mathrm{OA})$ converter $[11,12]$ being further improved with collisional cooling and accumulation of ions in radio-frequency ion guides [13, 14]. Nowadays,

*Correspondence Address to this author at the MSC-CG, A5, JNA blv, Bar, 85000, Montenegro; Tel: +382 69745890;

E-mail: anatoly.verenchikov@gmail.com
TOFMS are widely used with MALDI ionization, and as a second stage of tandems like Q-TOF $[15,16]$.

Resolving power of TOFMS dramatically improves in multi-turn $[17,18]$ and multi-reflecting (MR-TOF) analyzers [19, 20]. However, performance of such analyzers were limited either by high aberrations of electrostatic sectors [18], or by narrow mass range in looped schemes $[17,19]$ or by ion losses due to ion packet divergence [20].

The authors have conducted decade-long research and development with the goal to extend the resolving power and throughput of the MR-TOFMS in single MS and tandem MS-MS configurations. The review of these efforts is the main focus of this publication which details could be found in corresponding patent applications [21-50], published articles and conference presentations [51-112]. Though similar review on the whole area of high resolution TOF and high throughput multiplexing methods is highly desirable, authors excuse themselves for not writing the book-size manuscript but rather concentrating on the review of the own yet unpublished results.

The review does not present an detailed technical description of individual methods or techniques, but refers to original various publications. The goal of this review is to combine the related methods and to help readers in grasping the wide scope concept, understanding the unity of the overall approach and to get inspired for the further progress.

Discovering the method of indefinite ion confinement within an array of periodic lens [51-53] allowed solving the problem of ion losses in planar MR- 
TOFMS and to propose an effective ion optical scheme of planar MR-TOFMS [24-26, 54-59]. In our earlier experiments [60-64] we implemented the indefinite ion trapping regime within the MR-TOFMS analyzer and demonstrated the resolving power up to $1,000,000$ [65]. The MR-TOFMS analyzer has been adopted for continuous ion beams via so-called double orthogonal acceleration approach to ion introduction [26, 66-75], which sensitivity was further improved with velocity modulation within ion guide [26, 28, 29, 76, 77]. In the described here experiments, the mass resolving power of the MR-TOFMS was brought to $R=200,000$ at full mass range, thus, providing wealth of mass spectral information and improving mass accuracy to sub-ppm level. Aberration limit of the MR-TOFMS was experimentally shown to reach $R=500,000$ in a socalled 'Zoom' mode, while trapping ions in MR-TOFMS for multiple passes.

Many proposed improvements are likely to push the MR-TOFMS resolution even further. The recent developments have brought isochronicity of ion mirrors to full third order focusing and fifth order energy focusing [38, 44, 78-80]. The so-called "quasi-planar" ion mirrors with curved electrostatic fields $[30,50,80]$ are expected to compensate aberrations of the periodic lens. Cylindrical analyzers [33-35, 37, 41, 43] provide yet even more compact trajectory folding to reach ions' flight path of hundreds of meters within rather compact mass analyzers. An axial bunching [48] opens the way to generate sub-nanosecond ion packets and significantly improve the MR-TOFMS duty cycle.

Combination of high-resolution MR-TOFMS coupled with comprehensive GCxGC chromatography [81-83], and in particularly while combined with soft and quantitative ionization using 'conditioned glow discharge' source [32, 84-86], brings the effective separation capacity over $10,000,000$, which is quite useful for analysis of ultra-complex mixtures. The utility of such approach has been demonstrated by detecting over 300,000 species in crude oils samples [83].

The MR-TOFMS was also considered for using in development of all-mass tandems MS-MS, avoiding ion losses due to scanning of precursor ions. At very early stages of MR-TOFMS based instruments development we have proposed a method of time-nested TOF-TOF or Comprehensive TOF-TOF (CTT) [22, 23, 61, 87-89], where the first MR-TOFMS separates precursor ions at $10 \mathrm{~ms}$ time scale, and the second TOF sequentially analyzes ion fragments at 10 us time scale. It was found that short high gas pressure CID cell was capable of transferring fragment ions at such short time scale [98-101]. Experimentally it was found [90-97] that intensive ion packets (up to $1 \mathrm{E}+6$ charges per packet) produced by an axial trap, expand in MR-TOFMS, which limits the ion flux into a CID cell, thus, defeating the advantage of the parallel fragment analysis by CTT. The CTT approach was further advanced with proposal of using a surface induced dissociation [41, 102, 103] for fragmentation of the precursor ions, which could accept wide ion packets without gas load into MRTOFMS. To improve the throughput, there was proposed a method of non-redundant parallel sampling of multiple parents, employing several levels of spectral encoding [41].

Complexity and limitations of Comprehensive TOFTOF tandems drove our attention to alternative MS-MS schemes, where the first mass separator may employ either quadrupole filters, or ion traps, or ion mobility separators. This approach requires ultimate sensitivity and speed of the second mass analyzer. To overcome the low duty cycle properties of MR-TOFMS with orthogonal accelerators (OA), we proposed and tested axial trap converters [90-97] with trapping ions by radial $\mathrm{RF}$ and axial DC fields. Indeed, the scheme allows effective use of small ion fluxes in MS-MS tandems [94, 95], but being limited in MS-only analyses mode by space charge capacity of the trap pulsed converter and of MR-TOFMS [96, 97].

Introduction of the Encoded Frequent Pulsing (EFP) method [36] for robust orthogonal acceleration improves the duty cycle of the MR-TOFMS with OA and addresses space charge limitations. The EFP method improves sensitivity, dynamic range and speed of analysis by up to two orders of magnitude [104, 105]. This paper demonstrates detection and identification of minor target species at low femtogram amounts of analyte. The paper also presents an idea of applying the EFP method to so-called 'open traps' [35, 36], expected to further improve the dynamic range of MSMS analyses.

The EFP method brings another advantage to the analysis: speed of ion flow tracking, useful, for example, for recording time profiles past mass or mobility separators. This opens the opportunity for very effective analysis using multiple parallel all-mass tandems. A moderate sensitivity improvement may be obtained at so-called two-dimensional MS-MS analysis $[45,47]$, experimentally tested on the Q-MR-TOFMS research-grade instrument. The quadrupole separator of precursor ions is smoothly scanned with a wide (10- 
30amu) mass window. The effective dwell time is increased proportional to the mass window width, while accurate time profiles for parent and fragment masses, obtained at 10 us period in EFP method, allow the accurate reconstruction of fragment spectra and recover unit mass resolution of parent separation. The method provides all-mass MS-MS with sensitivity and dynamic range being improved proportional to the width of the parent mass window scan.

Yet even higher efficiency of MS-MS tandems is expected with lossless parent ion separations, proposed in [39, 42, 46]. To handle large (approaching $1 \mathrm{E}+9 \mathrm{ion} / \mathrm{sec}$ ) ion fluxes commonly observed in the modern ion source, we proposed [46] using an array of parallel linear ion traps for all-mass MS-MS, followed by MR-TOFMS operating in the EFP mode.

Early experiments with double encoded IMS-MRTOFMS [106] have demonstrated the feasibility of the method and have shown the correlation of ion mobility with ion mass defect. The early prototype had limited charge throughput capabilities of the ion mobility stage, which will be a subject of further experimental optimization. The parallel and lossless IMS separation may be used for either 3D-tag analysis (chromatographic retention time, mobility and accurate mass tags) or for a lossless all-mass MS-MS within the same instrument.

Use of multiplexed arrays of MR-TOFMS analyzers $[33,34]$ presents yet another dimension of multiplexing. The array of analyzers could use identical electrode structures and share the same power electronics and vacuum system.

Summarizing all above, the multiplexing approaches in MR-TOFMS technology bring an opportunity for substantial improvements in throughput of MS and MSMS analyses. In addition to parallel spectra acquisition (i.e. 1st multiplexing dimension) the described multiplexing dimensions are:

- Multiple reflections in TOF MS analyzers for improving TOF resolution;

- Multiple stage chromatographic separation for higher separation capacity;

- $\quad$ Time-nested comprehensive TOF-TOF tandems for all-mass MS-MS;

- $\quad$ Parallel TOF-TOF tandems with non-redundant sampling of multiple precursor ions;
- $\quad$ Encoded Frequent Pulsing (EFP) for improving MR-TOF duty cycle and for higher speed and dynamic range in parallel tandems;

- $\quad$ An alternative EFP method for open traps for improving sensitivity in tandems;

- $\quad$ Two-dimensional MS-MS in Q-MRTOF with wide open quadrupole windows;

- Parallel IMS-MRTOF for acquiring tandem spectra for all precursor ions;

- IMS-MRTOF identification with three tags: retention time, mobility and exact mass;

- $\quad$ All-mass MS-MS with a lossless ion trap array, supported by EFP MRTOF;

- $\quad$ Array of MRTOF analyzers for yet higher throughput;

- Electrostatic traps and open electrostatic traps for higher ionic currents.

\section{PLANAR MULTI-REFLECTING TOFMS WITH FOLDED FLIGHT PATH (FFP $\left.{ }^{\circledR}\right)$}

In a singly reflecting TOFMS, the turn-around time originating in the ion sources is the sole first order aberration of TOF mass spectrometers and the primary limiting factor for TOFMS resolution. The turn-around limit of the resolving power may be expressed as [63]:

$$
R<(\Delta K / K)^{*}\left(L^{*} V\right) /\left(\Delta X^{*} \Delta V\right) / 4,
$$

where $\Delta K / K$ is the relative energy tolerance of the analyzer, $\Delta \boldsymbol{X}^{\star} \boldsymbol{\Delta} \boldsymbol{V}$ - ion beam emittance before the pulsed acceleration, and $L^{*} \boldsymbol{V}$ - analyzer acceptance with $\boldsymbol{L}$ meaning the flight path length and $\boldsymbol{V}$ being the average ion velocity in the drift region. The expression highlights the least used resource for improving resolving power - longer flight paths in TOF analyzers. Obviously, some form of ion trajectory folding is required to reach a substantial increase in the flight path, say tens of meters, if we want to stay within laboratory-size instruments dimensions.

Various multi-turn and multi-reflecting schemes [1720] have been explored in the past, with most of designs either being limited by a narrow mass range or high aberrations (e.g. in electrostatic sectors). Multiple reflections between planar mirrors, proposed by Yakushev et al. [20], allow both multiple mirror reflections (i.e. increased ion path length) and 
arrangement of the ion path along the mirror symmetry plane (i.e. unlimited mass range). However, the practical use of that scheme was limited by the ion packet divergence along the drift axis.

To address problems of the prior art multi-pass mass spectrometers [17-20], authors have developed a Multi-Reflecting Time-of-Flight mass spectrometer with Folded Flight Path (MR-TOFMS) [24, 25, 54-59], depicted in Figure 1-A. The analyzer employs a pair of gridless electrostatic ion mirrors separated by a drift space. The ion mirrors are extended in the drift Zdirection to form a two-dimensional planar electrostatic field in the $X Y$ plane, similar to [20]. The mirror field is optimized to provide an isochronous ion motion in the $\mathrm{X}$-direction and spatial ion focusing in the $\mathrm{Y}$-direction, while providing the aberration limit of analyzer resolution exceeding one million [38, 44, 65]. Comparable resolution is theoretically predicted and is experimentally achieved in trapping coaxial MR-TOF employed in nuclear physics research $[111,112]$.

To avoid natural ion packet divergence in the drift direction, the MR-TOFMS scheme is further improved by using an array of periodic lenses [24, 25]. As it has been shown in [51-53], the periodic lens provides an indefinite ion packet confinement along the mean zigzag ion trajectory. Though the lens introduces aberrations, such aberrations are moderate for practical ion packet widths and divergences. These aberrations are further reduced when ion packets are created narrow in the Z-direction. For this goal, the socalled double orthogonal acceleration scheme $[26,66-$ 75] arranges the incoming ion beam substantially along the $\mathrm{Y}$-axis, i.e. orthogonal to the plane of the zigzag ion trajectory. Simulations suggest that such ion-optical geometry is capable to provide of up to $\mathrm{R}=500 \mathrm{~K}$.

The described ion optical scheme of the planar multireflecting TOF mass analyzer with periodic lenses and double-orthogonal acceleration was commercially implemented by LECO Corporation (St. Joseph, MI, USA) in the Citius LC-HRT [113] and Pegasus GCHRT [114-117] mass spectrometers.

With implementation of ion mirrors providing overall third order TOF focusing and $4^{\text {th }}$ order TOF focusing with respect to energy, the flight path in a $1 \mathrm{~m}$ long

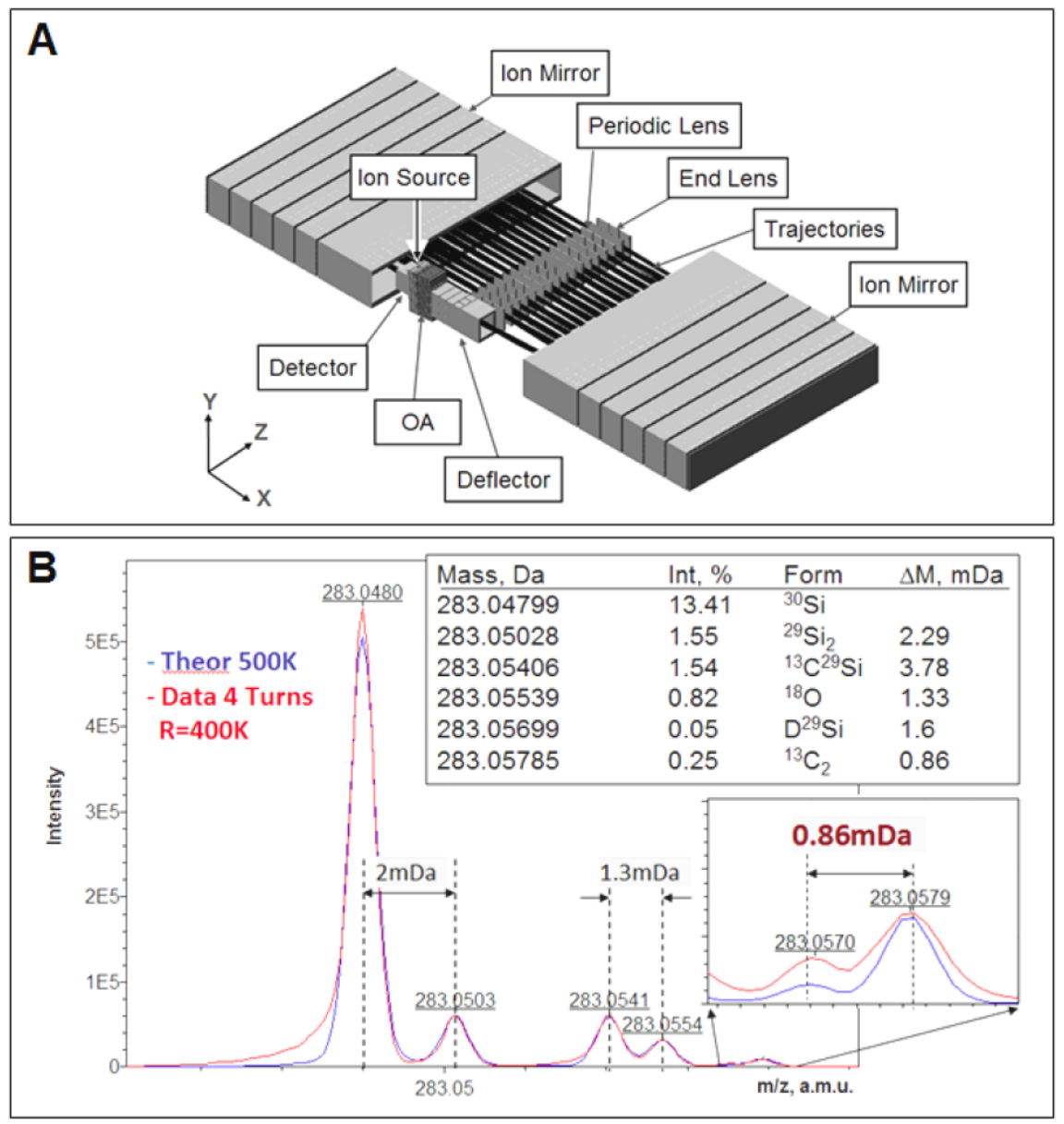

Figure 1: 
instrument is over $25 \mathrm{~m}$. Further on, with repetitive passing ions through the instrument in the zoom-in mode as explained below, the $100 \mathrm{~m}$ long flight path was reached in an experimental test of the P-MR-TOF analyzer. In Figure 1-B the obtained spectrum of an isotopic cluster of GC column bleed compound $\left(\mathrm{C}_{7} \mathrm{H}_{21} \mathrm{O}_{4} \mathrm{Si}_{4}\right)$, ionized with electron impact source, is compared to the theoretical isotopic pattern (blue line). It is shown in particular, that the obtained high mass resolving power of $500 \mathrm{~K}$ allows observing fine isotopic pattern with less than $1 \mathrm{mDa}$ mass difference.

As seen in Figure 2, the same instrument provides resolution $\mathrm{R}>200 \mathrm{~K}$ in the full mass range mode. Inserts $A$ and $B$ show the difference between modes of mass analyzer operation. In the full mass range mode (insert A) ions are flown for a single full pass: they leave the orthogonal accelerator (OA), follow multiple reflections in one drift direction (from top to bottom in Figure 2A), then got reflected by the electrostatic electrical field of the end-lens and return by the same route to the detector. There is no trajectory looping, thus this mode allows acquisition of the full mass range. However, the ion path is not long enough to reach the aberration limit of the analyzer and thus the dominant contributor into the time width of the ion signal peaks at the detector is the initial time spread of the ions when they leave the $O A$. When pulsing the voltage on the entrance lens (shown as "pulse" sign), ions could be "trapped" within the analyzer for a number $\mathrm{N}$ of full passes (turns), thus providing the so-called "zoom" mode. The ion flight path becomes longer and the resolving power increases, though at the expense of narrowing the admitted ions mass range. The plot on the Figure 2 shows that the resolution improves with the number of turns in the zoom mode, and reaches at least $500 \mathrm{~K}$ after five turns and then increase in resolution is significantly slows down and essentially stays flat at the level of aberration limit $R_{A}>500 K$.

\section{FUTURE IMPROVEMENTS OF MR-TOF}

Achieving yet higher resolving powers in MRTOFMS would require a longer flight path, smaller aberrations of the analyzer and narrower ion packets. Figure 3-A shows a concept of cylindrically wrapped planar MR-TOF analyzer [33, 34, 41, 43], which allows efficient folding of the ion trajectory within a relatively

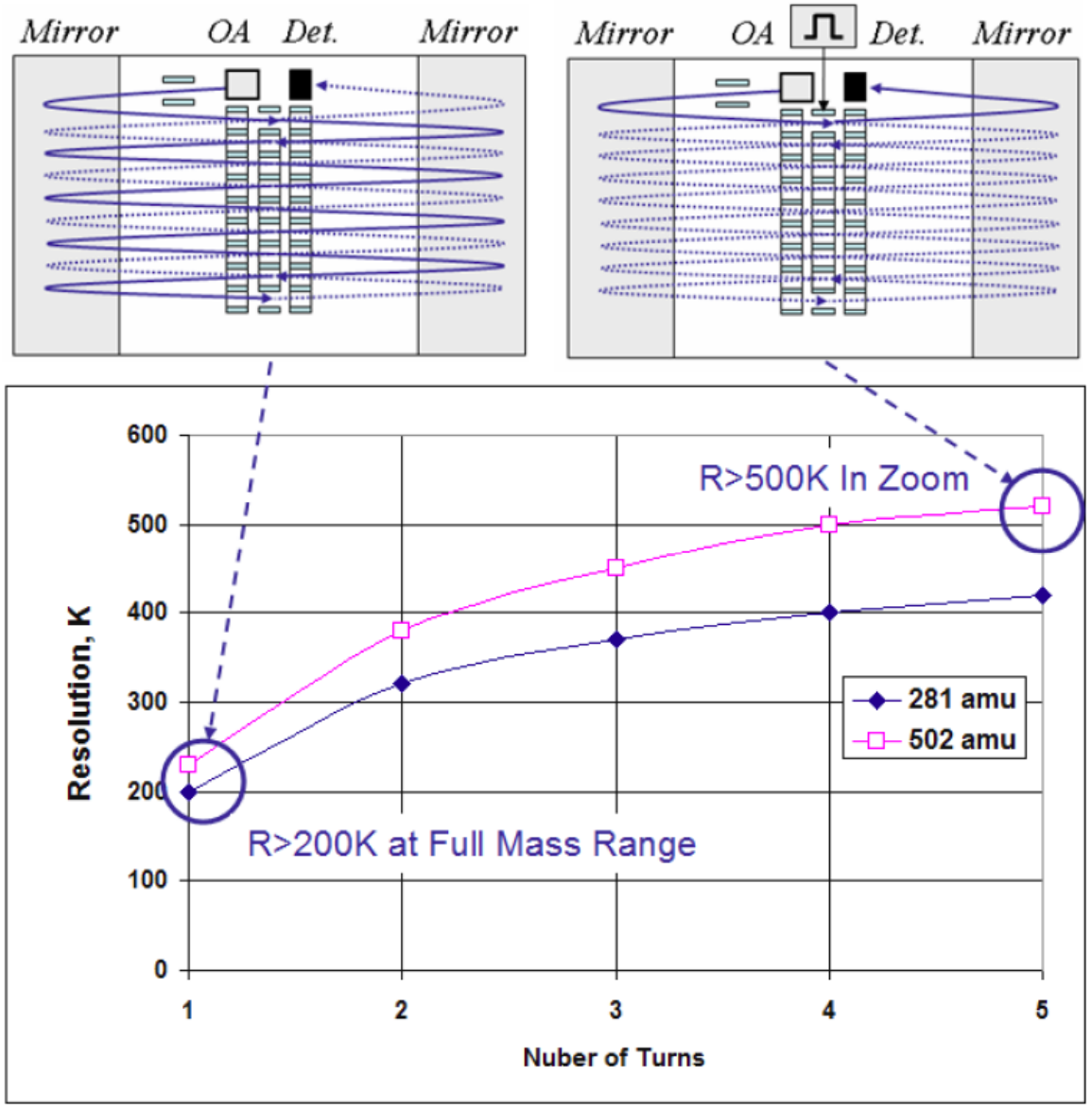

Figure 2: 

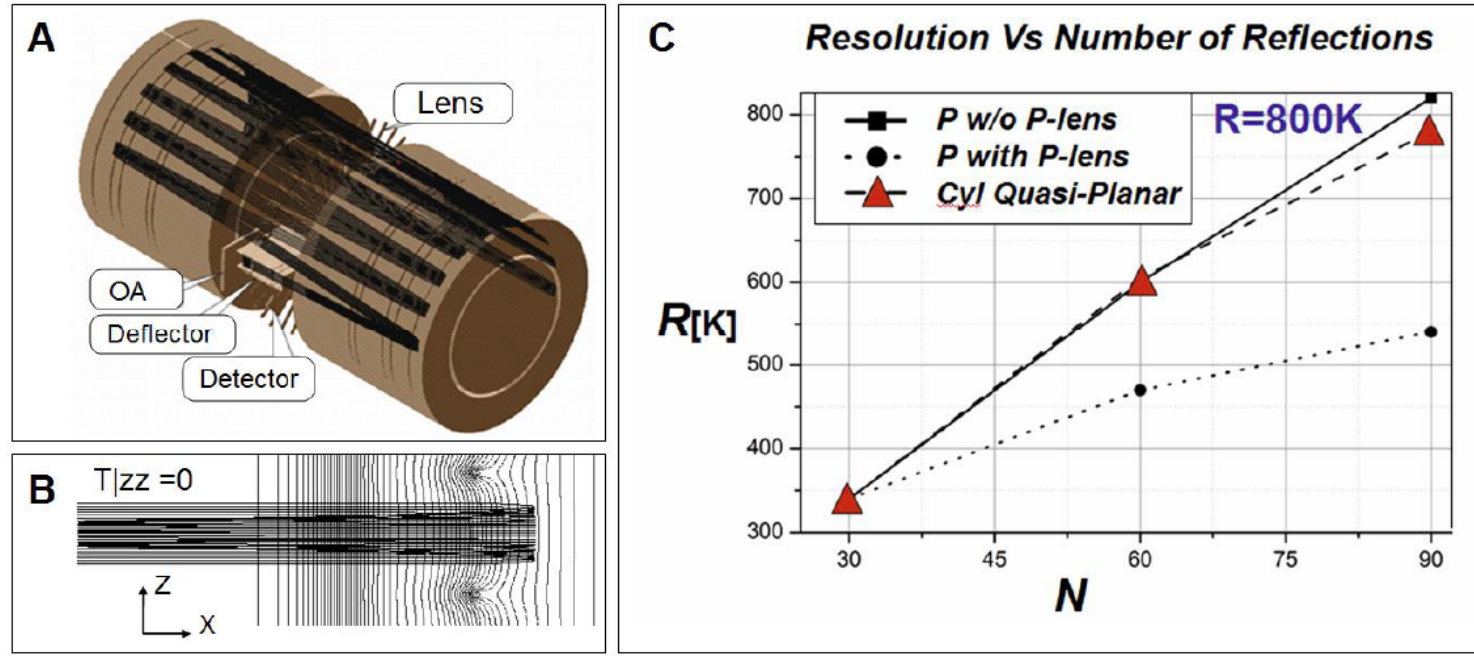

Figure 3:

compact-size analyzer. Ion optical simulations suggest that $100 \mathrm{~m}$ long flight path is obtainable inside $1 \mathrm{~m}$ long mass analyzer placed in $0.3 \mathrm{~m}$ diameter cylinder. Optionally, the cylindrical analyzer could incorporate a periodic lens array in the drift region: with $10 \mathrm{~mm}$ lens pitch the design could provide almost 100 reflections in the single ion pass. The simulations also suggest that the tangential ion packet displacement within the cylindrical analyzer does not affect the MR-TOFMS resolution up to at least $R_{A}=1$ million level in case of injecting ion packets at a small inclination angles, sufficiently large radius to length ratio of the analyzer and if an additional radial displacement of ions is arranged to return the ion turning point onto the symmetry plane.

Figure 3-B illustrates a concept of overcoming aberrations introduced by periodic lenses by arranging a so-called quasi-planar ion mirror [30, 80]. Small spatial modulations of the electrical field of the planar mirror could be achieved for example by incorporating auxiliary electrodes in the vicinity of ion reflecting point. Such electrodes help to create a small field curvature in the $X Z$ plane. The curved mirror electrical fields are known to provide spatial focusing in the $X Z$ plane with high order isochronicity as it has been demonstrated earlier for planar fields in the $\mathrm{XY}$ plane.

The plot on the Figure $3 \mathrm{C}$ show results of ion optical simulations for the analyzer incorporating quasi-planar fields of Figure 3B. It is shown that the resolution improves with number of ion reflections in all simulated cases. However, when using periodic lenses in the analyzer with planar or cylindrical ion mirrors, the resolution start being affected by lens aberrations at $R>300000$ and saturates at approximately $R=500,000$ -
600,000 level. When using quasi-planar ion mirrors, the resolution keeps improving to at least $\mathrm{R}=800,000$ at 90 turns and stays close to the aberration limit of the planar or cylindrical ion mirrors. Simulations suggest that resolving power of one million is achievable.

An alternative or complementary approach for achieving ultra-high resolution is shown on the Figure 4. Ultra-short ion packets can be obtained by using an axial buncher [48]. The Figure 4A describes the major steps of the method implementation: 1) A continuous ion beam is accelerated to high energies, thus strongly reducing an absolute velocity spread. Preferably, the beam is refocused for being a parallel; 2) The beam is pulse accelerated in the axial directions by a so-called axial buncher, where the moderate electric field strength is chosen to reach a sub-nanosecond turnaround time; and 3) An electrostatic energy filter selects ions accelerated in the middle of the buncher and thus, having a proper energy range, removes the continuous beam and excessive ions from edges of the axial buncher. Figure 4B shows an example of the axial gridless buncher, terminated by an exit lens to form highly parallel ion packets. Figure 4-C presents a simulated ion optical scheme, including an energy filter, simultaneously serving as a curved inlet into the MRTOFMS analyzer [27]. Figure 4D shows the simulated time profile of ion packets, formed by the arrangement of Figure 4C, justifying an ability to form subnanosecond ion packets.

\section{MULTI-DIMENSIONAL CHROMATOGRAPHY WITH MR-TOFMS}

Authors have recognized tremendous separation capacity of high resolution MR-TOFMS, particularly 

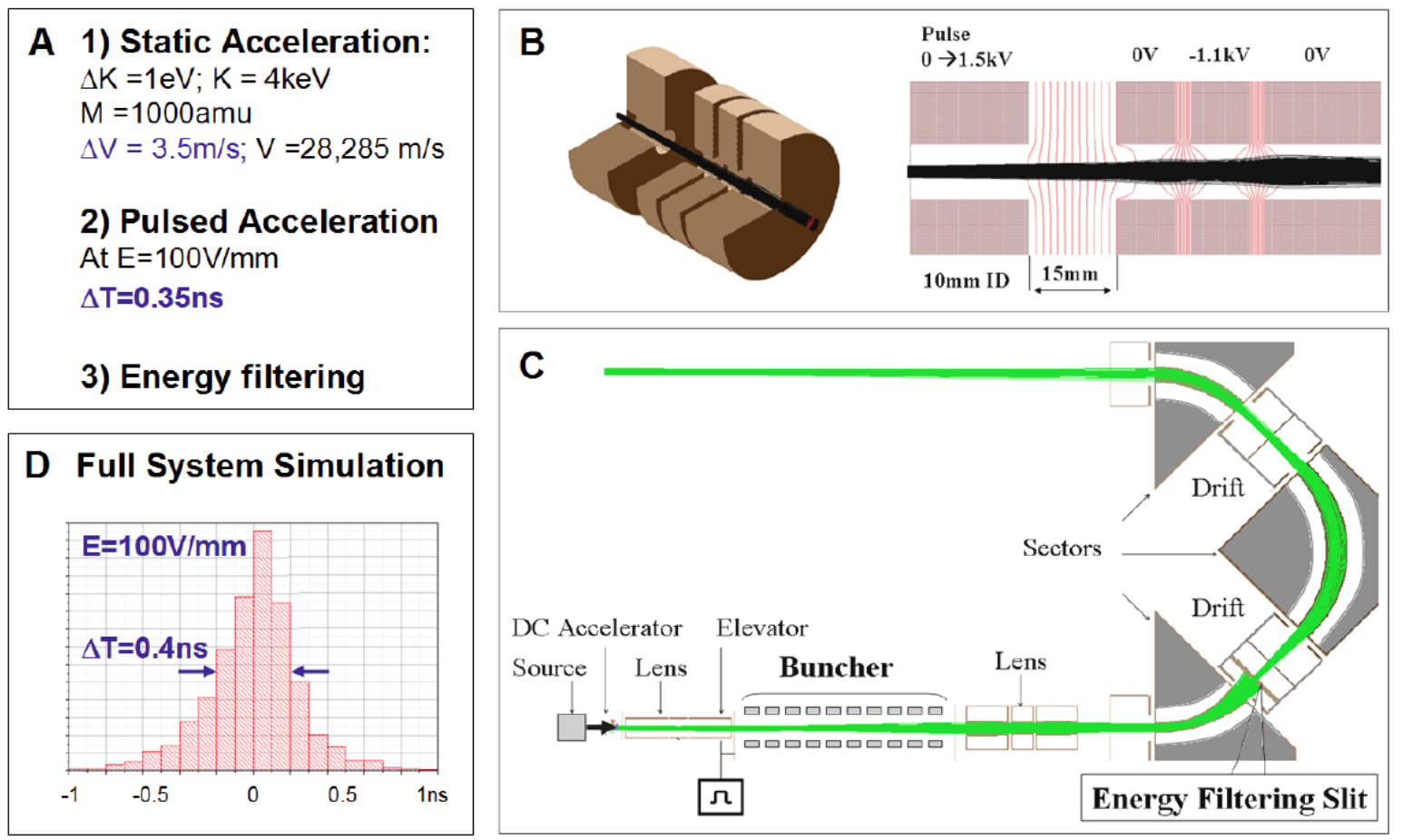

Figure 4:

when coupled with multi-dimensional chromatography and with soft ionizing sources to reduce the number of peaks per ion specie. Earlier [82-84], we reported the results of analysis of crude oils with MR-TOFMS while using soft ionization sources, like chemical photoionization $(\mathrm{PCl})$ or conditioned glow discharge (CGD) $[32,84-86]$ sources.

The experimental setup is shown on the Figure 5-A. The crude oil sample was diluted in $\mathrm{CCl}_{4}$ to $1 \%$ concentration and injected into GC or comprehensive GCxGC. Time separated semi-volatile compounds were chemically ionized by hexane ions, produced by photo-ionization using Xenon UV lamp. The mass spectra were collected on MR-TOFMS with dual orthogonal acceleration with resolving power over 100,000 . High resolution allows separation close isobars at 3 to $6 \mathrm{mDa}$ difference (e.g. pairs like $\mathrm{SH}_{4} / \mathrm{C}_{3}$, $\left.{ }^{13} \mathrm{C} /{ }^{15} \mathrm{~N}\right)$. Mass separated isobars allow accurate assignment of elemental compositions of the detected ions. In many cases very close isobars with 1-2 $\mathrm{mDa}$ mass difference (which is not enough to separate at the given resolving power) were eluted at different retention times and that accurate mass measurements were possible without isobar interferences.

After assigning elemental compositions, the spectra were analyzed with in-house software for extracting information about a set of detected compounds, corresponding to the same hetero-atomic class, for example, having single serum atom to be referred to as S-class. Within the set, the detected compounds were then differentiated by number of carbons $\mathrm{C}\left(\mathrm{CH}_{2}\right.$ mass difference) and by number of effective double bonds DBE $\left(\mathrm{H}_{2}\right.$ mass difference). Figure 5B shows an exemplar C-DBE plot for S-class ions with spot brightness corresponding to compound concentration in the sample. Notably, cyclic compounds with $\mathrm{DBE}=3$, 6 and 9 are most intense, probably meaning higher stability of cyclic compounds in the nature-formed reactor baking crude oils.

The elemental compositions with exact mass were then plotted as SIC (single ion current) plots, demonstrating their chromatographic separation, as shown in Figure 5C. The number of chromatographic peaks roughly corresponds to the number of possible structural isomers, confirming that the natural reactor creates all possible isomers. When comparing analyses results of different oils we have found that the isomeric distribution may be used for the fingerprint identification of the oil origin. The overall number of identified species, taking in account separated isomers was estimated in the 100,000 range.

While single stage gas chromatography (GC) is known to provide the separation peak capacity up to 1000 , the comprehensive GCxGC is known to increase the separation capacity up to 10,000 . In a typical setup, the first GC stage in GCxGC separates molecules by 

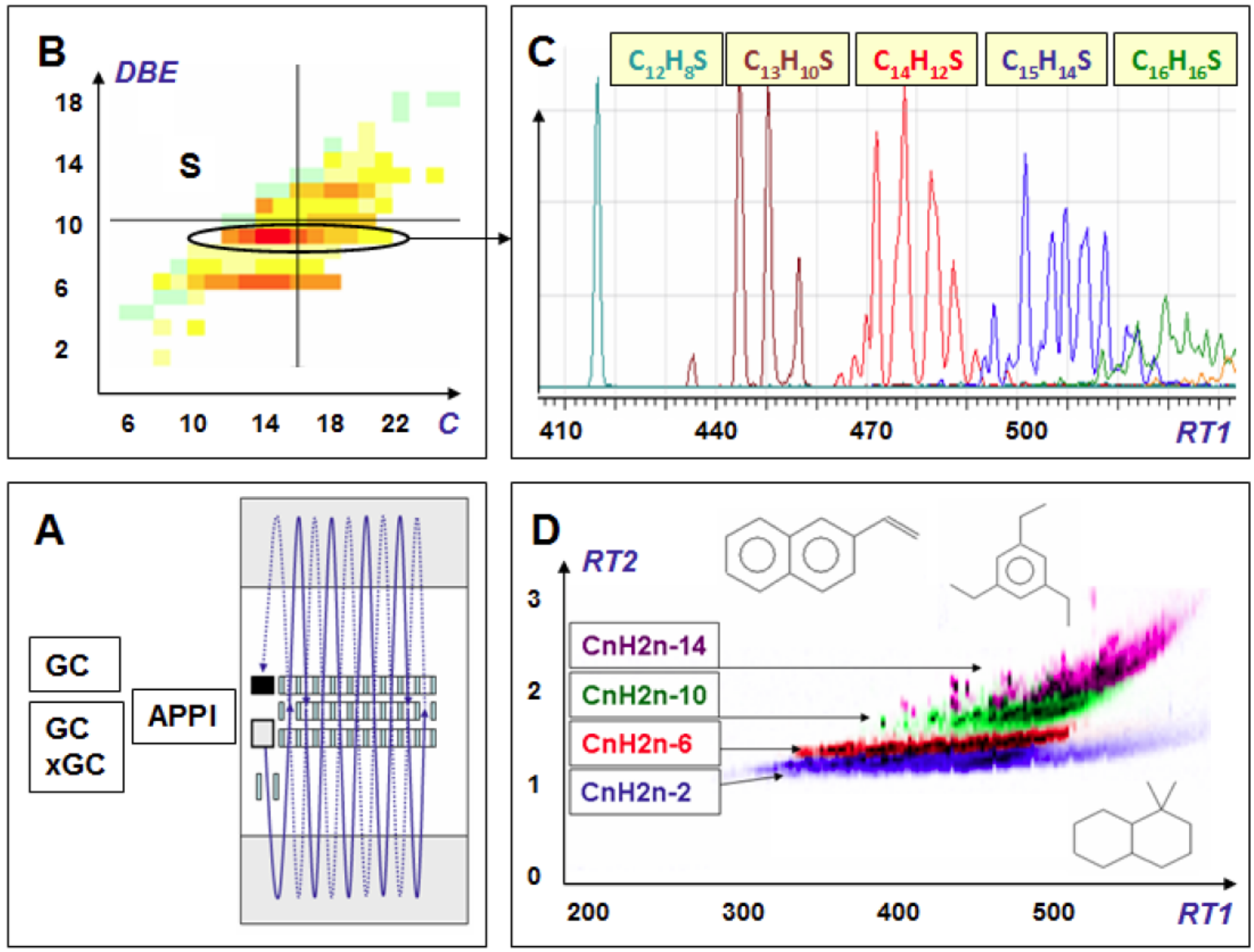

Figure 5:

volatility, while second GC by their polarity, thus providing characteristic patterns on the twodimensional (2D) plot indicating chemical classes. A soft APPI ionization provides only molecular $\mathrm{M}+$ or quasi-molecular ion peaks for most of the crude oil species and high resolution MR-TOFMS enhances the separation capacity by factor of 10,000 , bringing the overall separation capacity to approximately $10^{8}$. Figure 5-D shows a color-coded overlapped GCxGC plots for different hydrocarbon series. Accurate mass measurements in MR-TOFMS allow extracting 2D GCxGC plots for individual compounds, each having rich isotopic composition. With GCXGC-PCI-MRTOFMS we have detected over 10,000 elemental compositions and at least 300,000 species of crude oil, if accounting chromatographically separated isomers.

The $\mathrm{PCl}$ source has an advantage of selective ionization, which helps analyzing $\mathrm{S}-, \mathrm{N}$ - and O-class compounds at the trace levels; however, the ionization selectivity turns into a drawback if quantitative measurements are desired. In order to achieve a uniform ionization efficiency across the compounds of interest and to detect non-polar species (e.g. saturated hydrocarbons), we have developed so-called "conditioned glow discharge" ion source [32, 84-86]. The method employs Penning ionization in the argon atmosphere to provide exclusively $\mathrm{M}^{+}$molecular ions accompanied by limited fragmentation, including such classes of compounds as for alkanes, phthalates, and nitro compounds. When in-source collisional fragmentation is applied, resulting mass spectra appear very similar to the corresponding spectra in the standard libraries (NIST, Willey, etc). A combination of soft ionization, NIST identification of fragment spectra, and quantitative analysis presents a novel opportunity in analytical chemistry. The method may be particularly suitable for the analysis of crude oils, for quantitative metabolomic measurements and analysis of other complex mixtures types.

\section{COMPREHENSIVE TOF-TOF MASS SPECTRO- METER (CTT-MS)}

The idea of all-mass MS-MS analysis has been long intriguing. Parallel MS-only analysis has been already known while using TOFMSs, ion traps and IMS, all operating with ion trapping and mass separation in time paradigm. The challenge was to make a tandem operation of two trapping "in-time" separators, with the 
major technical challenge to make such a tandem truly lossless and handling realistically large ion fluxes, reaching $10^{9}$ to $10^{10}$ ion/sec generated by modern ESI and $\mathrm{El}$ ion sources.

Accumulating precursor ions in ion traps for sensitive MS-MS analysis was proposed in [21, 118]. This triggered an idea of using a three-dimensional ion trap for all-mass ion parent scan with downstream parallel fragment analysis by an orthogonal TOF [119]. The trap-TOF idea was then proposed in [120, 121]. However, it was quickly recognized that traps are too slow and their space charge capacity is too small. The limited charge throughput of the known ion traps would negate the sensitivity gain of the parallel MS-MS. The parallel IMS-TOFMS [122, 123] also might be considered too limited at the beginning. Based on the knowledge available in early 2000s, the scheme of time-nested TOF-TOF MS seemed being most prospective $[22,23]$.

The ion optical scheme of so-called Comprehensive TOF-TOF MS (CTT MS) $[22,23]$ is depicted in Figure
6. Ion flow is trapped in an axial RF trap, where ions are trapped by an RF field in the radial direction, and DC field of auxiliary electrodes helps trapping and pulse-ejecting ions in the axial direction. We have experimentally confirmed that the trap can operate at almost $1 \mathrm{kHz}$ frequency, while trapping up to $10^{6}$ ions, i.e. the charge throughput of the axial trap is very adequate to the analysis requirements. All parent mass species are then separated in time within a first multireflecting TOF mass analyzer (TOF1) at relatively low sub-keV ion kinetic energy to extend the flight time to about $10 \mathrm{~ms}$. The time-separated parents are then injected into the fragmentation cell (for example CID or SID type) and then are subjected to a rapid analysis in TOF2. The original idea was to use a short OA-TOF analyzer at high ion kinetic energies for a rapid TOF2 analysis. In a later proposition [41], the second TOF is a frequently pulsed MR-TOFMS.

The Figure $\mathbf{6}$ also depicts MS-MS spectra experimentally obtained in parallel all-mass analysis of a volatiles in perfume sample, ionized in APCI source. Experimental tests have revealed the challenging part

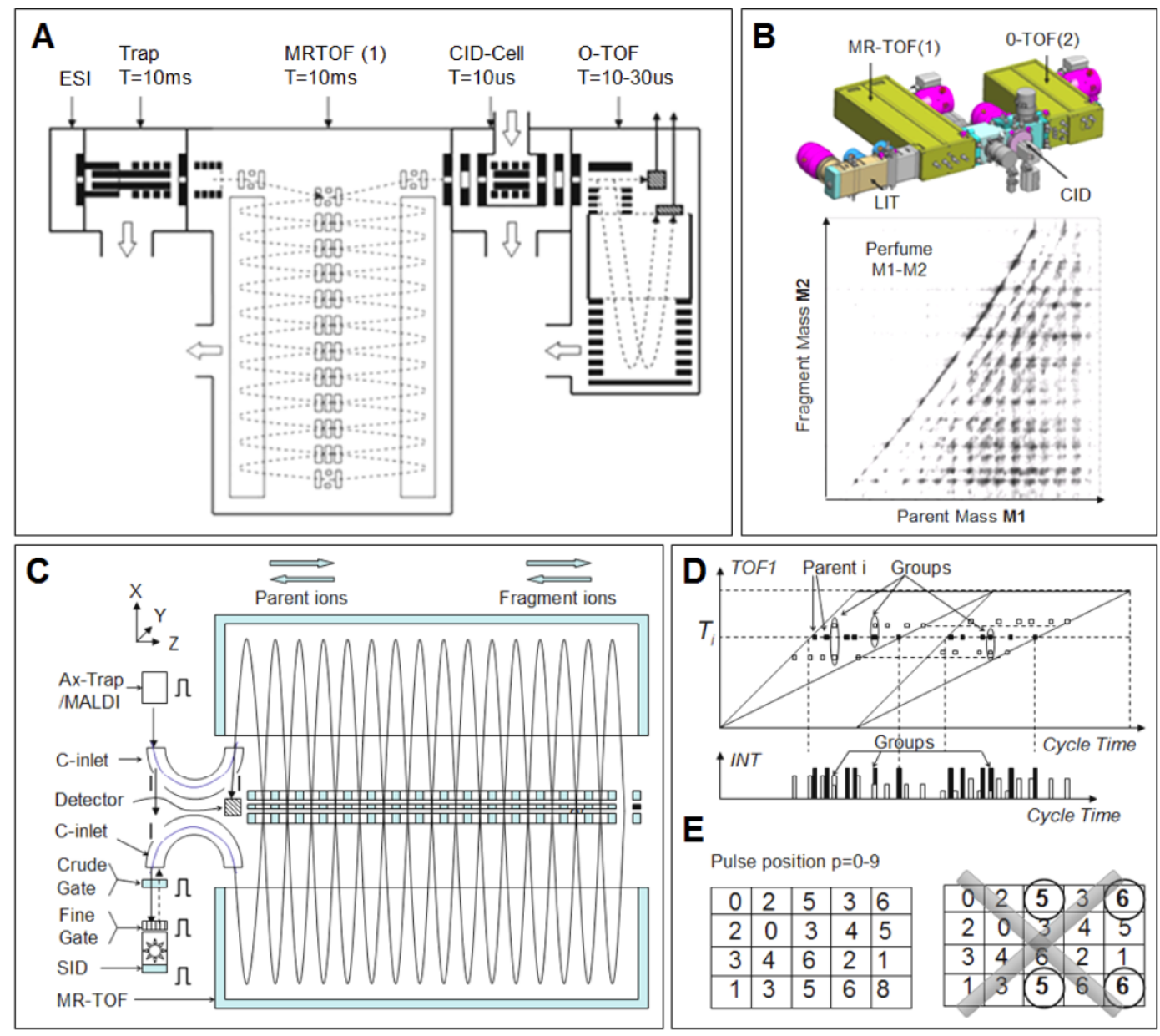

Figure 6: 
of the CTT MS scheme. The charge throughput appears to be limited by ion packets expansion due to space charge inside the MR-TOF analyzer, causing ion losses at the fragmentation cell entrance. Such losses start to occur at ion packets containing more than few thousand ions and the loss factor may reach 100 at the full space charge load. Spatial ion losses then negate the sensitivity gain of parallel analysis. Thus, the scheme may be useful only at reduced ion fluxes at the CTT MS entrance, for example, for $\mathrm{MS}^{3}$ analysis.

The issue of ion losses is expected to be solved in another MR-TOF-TOF tandem [41] reincarnation, shown in Figure 6-C. The CID fragmentation cell is replaced for in-vacuum SID fragmentation cell, which has much wider entrance aperture and no need to introduce collisional gas flow into the MR-TOF analyzer. If one is using nonvolatile fluorinated polymers to coat the collisional surface of SID cell, the fragmentation efficiency of such SID cell was experimentally proven to be above $40 \%$. To allow use of the same MR-TOF analyzer for both TOF1 and TOF2 stage, there was proposed a concept of socalled "non redundant sampling" [41]. The data acquisition experiment lasts for multiple (say 100 to 1000) pulses of an axial trap, or pulses of in-vacuum MALDI source. The set of crude and fine time gates samples multiple parents per every pulse of the source. The voltage on the SID cell is pulsed for obtaining delayed ion extraction, where the pulse timing is encoded similar to the EFP method.

The key concept of the non-redundant sampling method is to provide a high multiplexing gain of the MS-MS analysis. Multiple parents are sampled per every ejection from the ion source, and mass spectra for numerous precursor ions are multiplexed (combined) at the MR-TOFMS detector. To avoid the confusion during spectra decoding, the parents are multiplexed at different combinations, so that to combine the same pair of parents only once (Figure 6D). During the data acquisition, any single parent ion is selected multiple times, so that the corresponding fragment spectrum may be extracted by correlating the systematically occurring fragments. The method is constructed on pair-wise orthogonal Latin square matrices. Figure 6-E provides a simplified example of orthogonal and non-orthogonal matrices for multiplexing samples 1 to 8 in multiple sequential experiments shown by horizontal rows. The second incorrect matrix repeats the pair of 5th and 6th samples.
The described method is expected to provide unusually high resolution of parent ion selection, in the order of several thousands, though at limited (5-10\%) duty cycle. The method implementation would require developing of multiple novel hardware components and plenty of special software operating new algorithms.

\section{ENCODED FREQUENT PULSING}

It's been long recognized that sensitivity of TOF MS with orthogonal accelerator (OA) may increase at higher frequency of $O A$ pulsing. However, that may cause spectral overlay, and for long time there was no effective solution for decoding of those overlapped spectra. The methods based on analysis of peak width [124], or single shift of pulsing frequency [125] can only work for high intensity peaks. Hadamard transformation (HT), earlier developed for IR spectroscopy [126], was proposed for mass spectrometry [127, 128], but the implementation was overlooking the fact that the HT method is suitable only for smooth spectra at narrow dynamic range. The automated addition and subtraction of peaks at "wrong" spectral position would leave the residual signal, if considering statistical variations only and not speaking of other artifacts.

We have departed from the "blind" mathematical algorithms and proposed a method derived from the "logical" analysis of spectra overlaps, occurring in MRTOF MS FFP spectra, which characterized by sparsely populated sharp (well resolved with high resolution) ion signal peaks [33, 34]. High resolution spectra appear to be relatively low populated, particularly at short acquisition times, insufficient for revealing the chemical noise at $1 \mathrm{E}-4$ to $1 \mathrm{E}-5$ level relative to strong analyte signals. At the same time, a prolonged flight time in MR-TOFMS and a relatively small size of ion packets both reduce the efficiency of the double orthogonal accelerator (duty cycle) under $D C<1 \%$, as shown in schematic view of Figure 7-A. In the exemplar case of $1 \mathrm{~ms}$ flight time and $50 \mathrm{eV}$ continuous ion beam, the duty cycle is estimated as $0.25 \%$ for upper $\mathrm{m} / \mathrm{z}$ range of detected ions.

In $[33,34]$ we proposed a solution for improving of the MR-TOFMS duty cycle - method of frequent pulsing of the orthogonal accelerator with unique time intervals (Encoded Frequent Pulsing - EFP). The key concept was that within overlaid mass spectra some overlaps are likely to occur between multiple peaks of various ion species. However, if time intervals between the $\mathrm{OA}$ pulses are unique, the overlaps will not be systematic! Figure 7-B compares time diagram for rare 


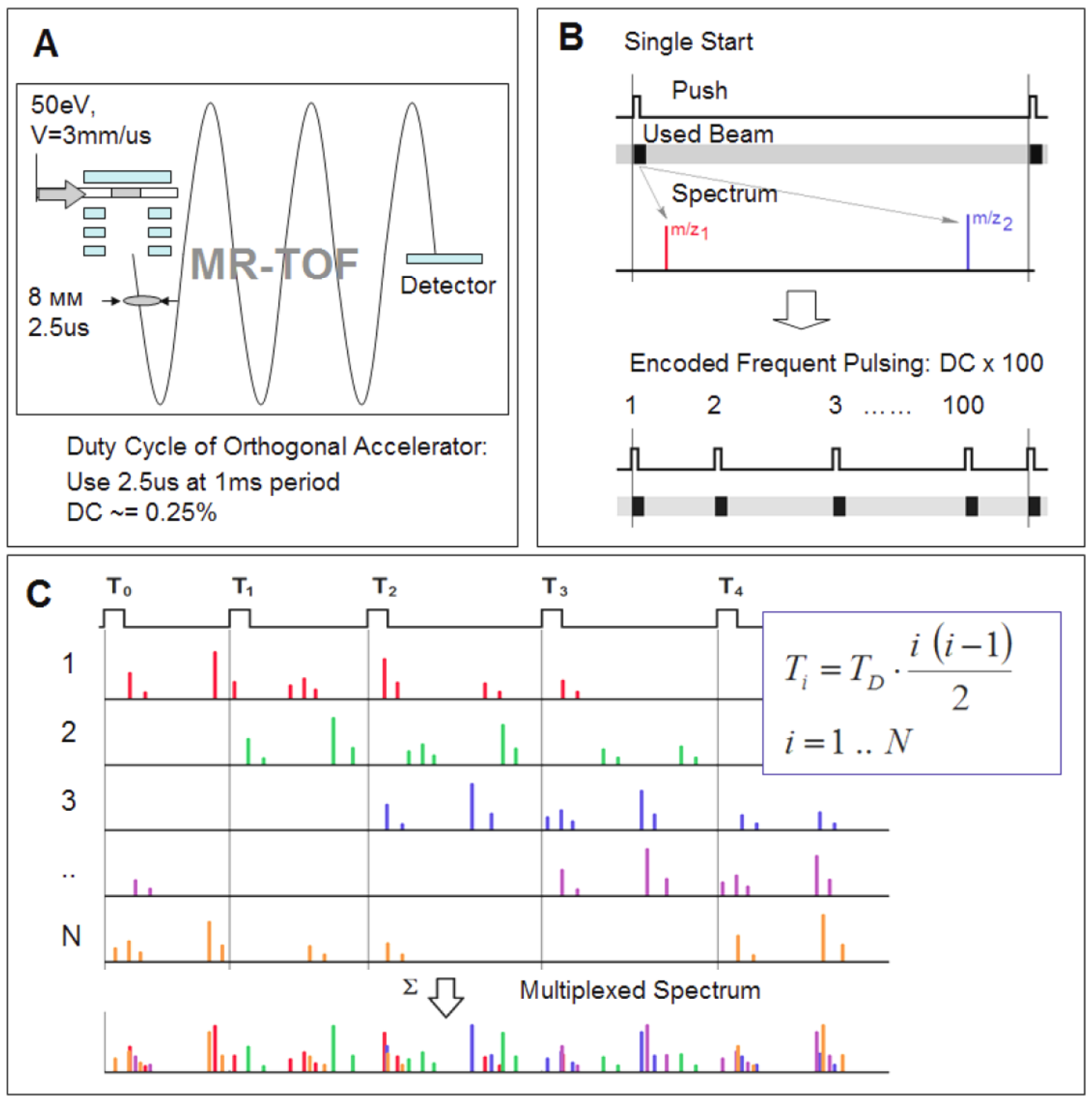

Figure 7:

pulses and encoded frequent pulsing (EFP). The grey bar represents a continuous beam with black sections denoting the used portion of the continuous ion beam. At frequent pulsing, the number of black portions rise dramatic, meaning that the continuous ion beam is sampled much more efficiently. In the presented example of 100 pulse sequences, the duty cycle is improved up to $25 \%$, which is very comparable to best implemented singly reflecting TOFMS with notably lower resolving powers.

The concept diagram in Figure 7-C shows how the multiplexed spectrum is composed from the multiple starts and from multiple ion species. The multiplexed spectrum looks like a mess, if trying to analyze it manually. However, the appropriate decoding algorithm knows the pulsing time sequence with one proposed example of pulse intervals as $T_{i}=T_{D}{ }^{*}{ }^{*}(i-1) / 2$, ensuring unique intervals between any pair of pulses. By knowing the expected peak intervals, the decoding (demultiplexing) algorithm collects all hypotheses into peaks of mass species, analyzes hypotheses for consistency of the intensity and accurate mass, and, optionally, analyzes the hypothesis for overlaps of the already detected mass species. There are multiple variations of the decoding algorithms, usually optimized for speed and efficiency.

Figure 8 presents an example of the sensitivity gain provided by implementation of EFP in MR-TOFMS operation. The trace amount of a drug is detected within a rich biological matrix and the results were compared between a single-start analysis data and data acquired with 68-pulse EFP. Expectedly, the absolute signal from the analytes grows proportional to the number of starts, as witnessed by the Total Ion 


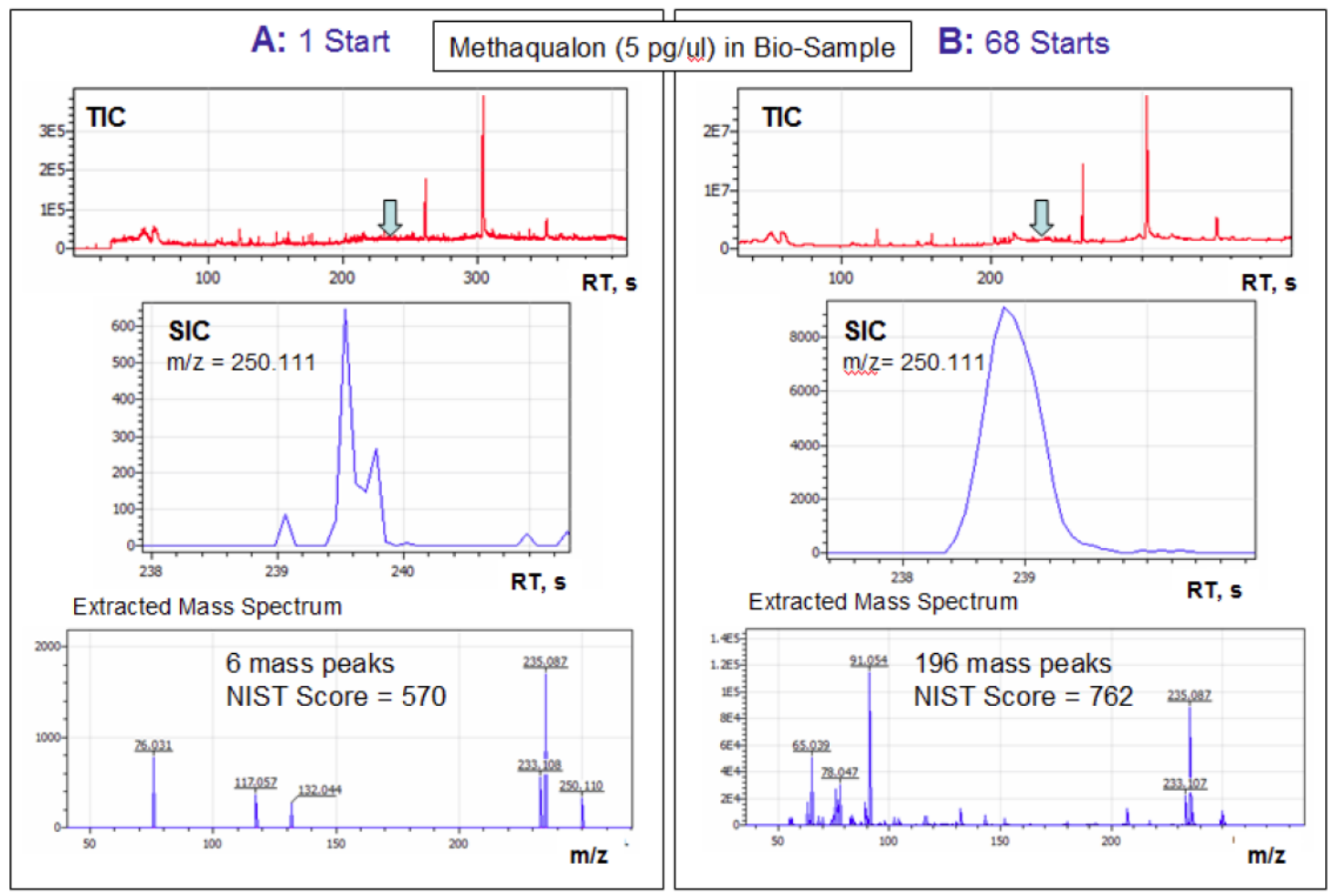

Figure 8:

Current (TIC) traces. Individual Single Ion Current (SIC) traces also grow proportional for strong mass components (not shown). For lower intensity components, the gain starts dropping, since the filtering part of the algorithm may reject very low signals, which potentially may be confused with signal composed of random overlaps. However, at $1 \mathrm{pg}$ analyte amount level, the EFP gain is still high (at least 30 for $\mathrm{m} / \mathrm{z}=250.111$ ), as seen from the inserts in the middle of the figure. Most importantly, SIC traces have a good statistics, which allows their deconvolution by retention time and this way extracting representative El spectra of the analytes, compared in the bottom plots. For example, in the shown data, while single start analysis allows reliably extract only 6 major peaks, the EFP analysis allows extracting 196 mass peaks within much wider dynamic range. As a result, the detection and identification is much more reliable. In the presented example, the NIST similarity score grows from 570 (no EFP) to 762 (with EFP).

The method of encoded frequent pulsing (EFP) does recover the duty cycle of MR-TOF and allows further extension of MR-TOF flight path (for example, in cylindrical analyzers as shown in Figure 3-A) without compromising sensitivity. The duty cycle is defined by the frequency of $O A$ pulsing rather than by the flight time in MR-TOF mass analyzers. The method extends the space charge limit of the analyzer and the dynamic range of TOF detectors. Finally, if analyzing the intensity distributions of the peak groups for any single ion specie, one can extract fine timing details and rapidly track time variations of ion flow in front of the MR-TOFMS. The fast signal tracking capability is particularly useful for accelerated profiling in surface image analysis, and in the fast parallel MS-MS and IMS-MS tandems as described below.

The drawback of the EFP method is in limitations due to high spectral population. According to our experimental tests, the method works very well for tandem mass spectra, which are usually scarcely populated. It also works well for MS-only analysis at short spectral acquisitions (under $100 \mathrm{~ms}$ per spectrum). However, the method fails when intense spectra are accumulated for seconds. However, in such cases, the single start spectra already provide detection down to chemical noise limit and there is no need to apply EFP. The switching between single start and frequent pulsing could be controlled in a data dependent strategy.

\section{FREQUENT PULSING IN OPEN TRAPS}

While choosing the methods of spectra multiplexing and de-multiplexing, the problem of low duty cycle in MR-TOFMS can be solved in an alternative way, being somewhat advantageous compared to the above EFP 
TOF = fixed flight path Vs OE-Trap = span in number of reflections

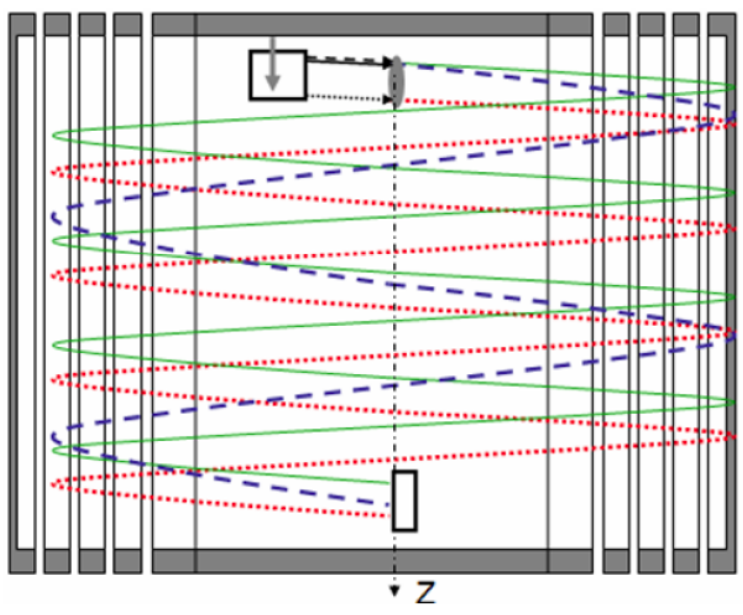

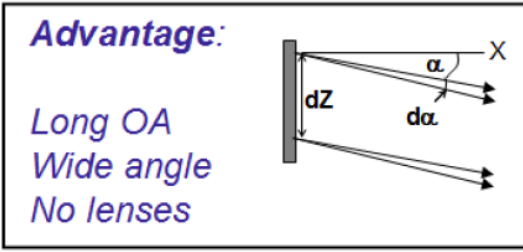

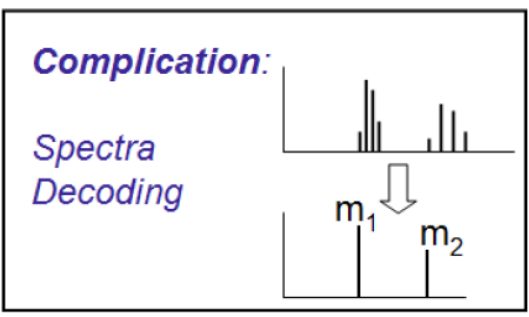

Figure 9:

method. In [35] we suggested Multi-Reflecting Open Traps (MROT), schematically depicted in Figure $\mathbf{9}$.

To understand the concept of MROT in Figure $\mathbf{9}$, they should be compared to multi-reflecting time-offlight mass spectrometers of Figure 1. In MR-TOFMS, the periodic lens confines ions along the mean trajectory, thus fixing the number of reflections and the length of ion trajectory and a single ion specie forms the single peak in the TOFMS spectrum. The peak multiplicity appears in EFP method (Figure 7), when the double orthogonal accelerator is pulsed frequently. In the Open Traps (Figure 9), the periodic lens is removed, and the number of reflections is not fixed because of the natural angular divergence of the ion packets and single specie rather forms multiple peaks corresponding to a span in the number of reflections. The ion peaks ensemble per single ion specie will have some intensity distribution per number of reflections (multiplexed peaks), expected to be a generic apparatus function for all mass species. The time period between ion peaks is proportional to square root of mass, thus, the systematic overlap between peaks of any two species is excluded, and open trap spectra can be decoded (de-multiplexed).

The multiplexing of MROT provides multiple advantages. Splitting single peak into multiple peaks and using wider ion packets overcomes space charge limitations of the TOF analyzer and improves the dynamic range of TOF detectors. Since ion packets are wide when they reach the detector, they can be formed wide in the orthogonal accelerator aligned in the drift Zdirection (see Figure 9), this way substantially improving the OA duty cycle. Using an elongated and dual side detector as described in [35] further improves the duty cycle and the dynamic range of the MROT. Finally, the MROT multiplexing may be combined with an encoded frequent pulsing of the $\mathrm{OA}$, as described in [35].

The MROT is also a quite efficient way for enhancing the resolution, since the periodic lenses are removed, thus removing their aberrations. Besides, the ion beam is narrow in the $\mathrm{Y}$ - direction, thus strongly reducing ion mirror aberrations contribution into the peak width. The Open Trap mass analyzer may be cylindrically wrapped one as shown in Figure 3 to provide an extended flight path and high resolution. One should note that extension of the flight path does not compromise the sensitivity. The only seen drawback of MROT is an inevitable use of multiplexed spectra. In other words, contrary to MR-TOFMS with EFP method, the Open Traps operation is not capable of switching between single start and multiplexed spectra acquisition modes.

\section{ION MOBILITY FOR PARENT SEPARATION}

Mass scanning losses have been a significant concern for MS-MS tandems operation. In triple quadrupoles, both quadrupole mass filters select and pass single mass specie in a time. This is an effective strategy for ultra-trace target analysis, where the parent and fragment masses are known up-front and are mapped per the expected chromatographic retention times. The Q-TOF instruments [15, 16] employ "allmass" TOF analyzer as MS2 to provide full information on all daughter (fragment) ions. However, first quadrupole separator as MS1, still spends time and 


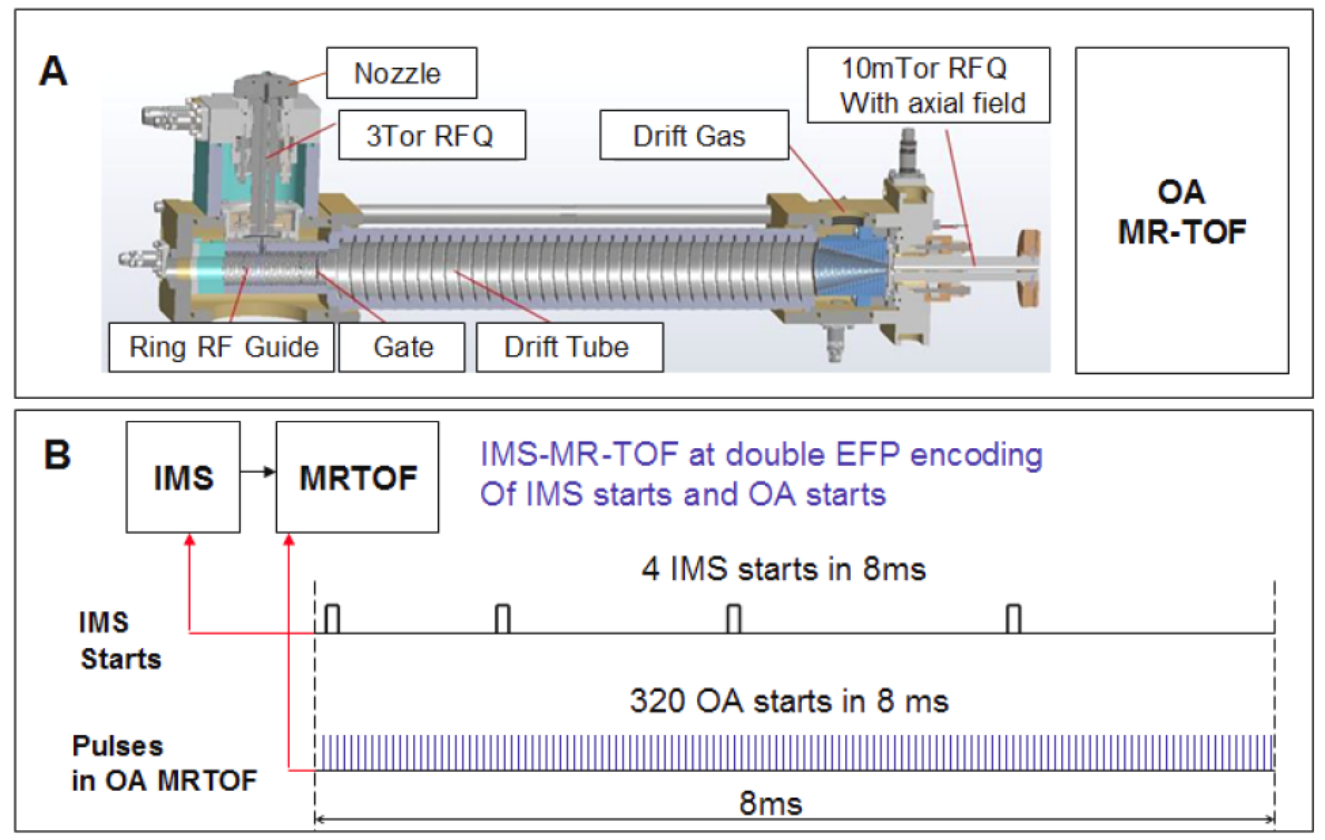

Figure 10:

loses other parent species when switching or scanning between parent masses. It is desirable to improve sensitivity while scanning or switching precursor ions.

One approach to parallel tandems has been proposed by Clemmer et al. [122, 123]. The precursor ions are trapped in an ion trap, pulsed-released, separated by an ion mobility spectrometer, optionally fragmented in a fragmentation cell, and then analyzed by a TOF mass spectrometer. Though the method was claimed to provide a parallel parent separation for allmass MS-MS analysis, the originally implemented apparatus had multiple limitations due to spatial ion losses, space charge spreading, and restrictions of a counting TDC data system, negating overall the gains of parallel separation. Since then, the multiple advances of the IMS-TOF were proposed and implemented, truly enhancing the IMS-TOFMS tandems [129-131].

We have proposed yet further enhancements of IMS-TOFMS performance by much faster tracking of ion mobility profiles with MR-TOFMS with FFP and with EFP [39, 42]. Figure 10-A shows a corresponding apparatus [106]. Electrospray ions are sampled via nozzle, delivered through the RF ion guide at 3 Torr and enter an accumulating RF ring guide. The RF ring gate [39] is used to release fast (100 us) ion packets into the electrostatic drift IM cell. lons are gathered by an ion funnel and enter into an MR-TOF via orthogonal accelerator using transfer RF ion guide at $10 \mathrm{mTor}$. The IMS-MR-TOF tandem employs the double encoding method $[39,42,106]$, where the intervals between IM pulses are not even and the orthogonal accelerator of the MR-TOF is pulsed with a much more frequent and also non-uniform string of pulses (Figure 10-B).

A time section of the doubly multiplexed mass spectrum is shown in Figure 11-A. Envelopes of at least two major mass components are visible. By knowing a predetermined non-uniform pulse sequence of the $\mathrm{OA}$, the decoding algorithm extracts mass spectrum, as shown in Figure 11-B. Tracking intensity profile for any single mass specie provides the multiplexed ion mobility profile. The IM profiles are then decoded based on the information of the predetermined pulse sequence of the IM gate. As a result, each $8 \mathrm{~ms}$ spectrum simultaneously provides the information on mass and mobility. A multiplicity of detected pairs $-\mathrm{m} / \mathrm{z}$ and mobilities - provide total mass spectrum 2D plot of Figure 11-C. In the tested example, most of the peaks are singly charged and mobility is heavily correlated with $\mathrm{m} / \mathrm{z}$, still, however, separating hydrocarbon and fluoro-hydrocarbon series. Surprisingly, mobility correlates with mass defect (Figure 11-D). For hydrocarbons it may explained by the effect of double bonding: each double bond removes a pair of hydrogen atoms (strong mass defect), while making the structure more compact, i.e. shortening the drift time in IMS.

Let us estimate the charge throughput of the IMMR-TOFMS tandem. The MR-TOFMS stage is limited to 300 ion/packet due to space charge effects in the 

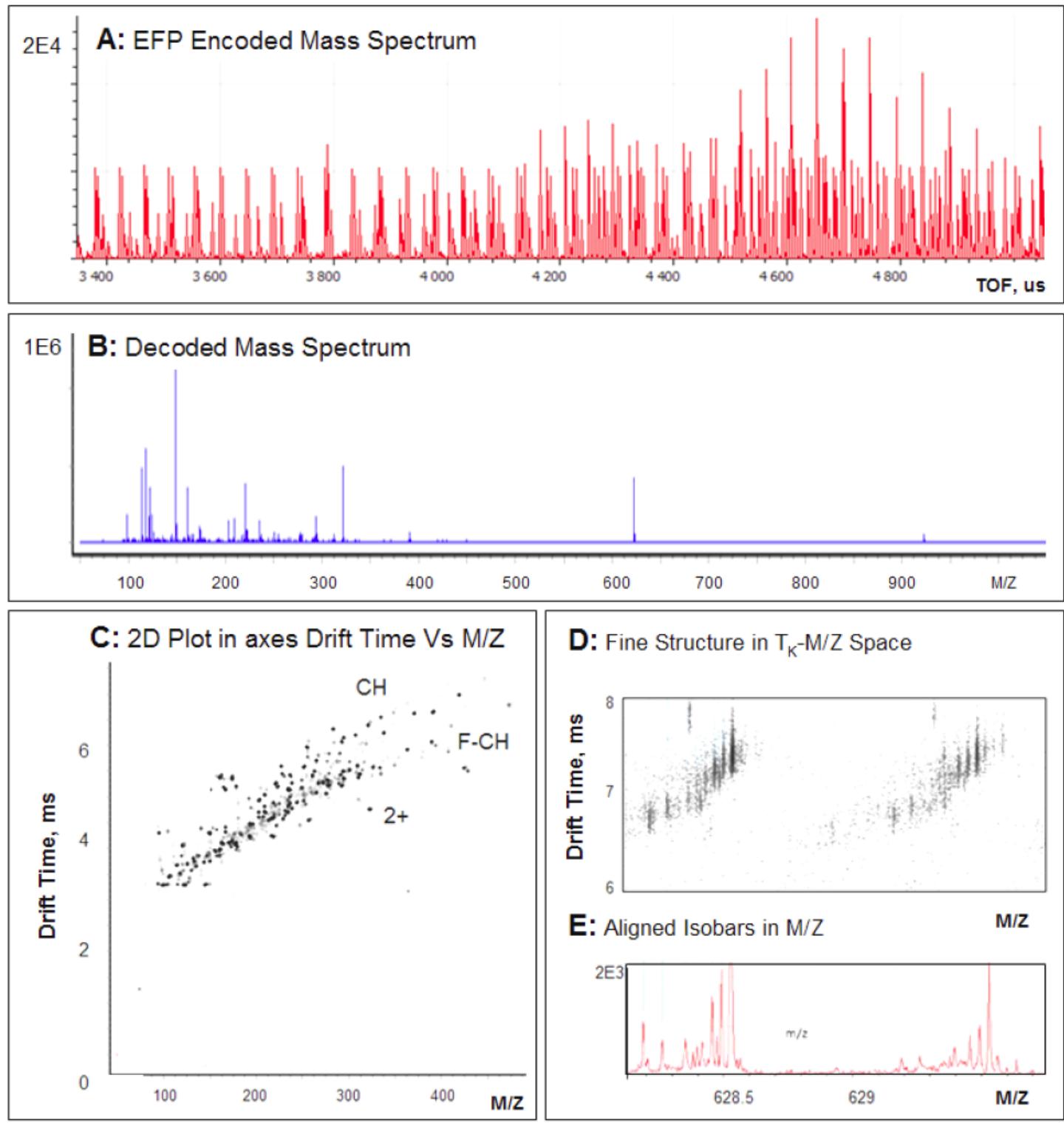

Figure 11:

analyzer and due to the limited dynamic range of the TOF ion detector. Accounting $100 \mathrm{kHz}$ average pulsing rate of the $\mathrm{OA}$, and assuming somewhat denser (than was experimentally implemented) pulsing of the IMS stage, the total charge throughput of the MR-TOFMS per ion specie can be estimated as $3 \times 10^{7}$ ions/peak/sec at the detector $[129,130]$.

The throughput of the IM stage has been measured as $150 \mathrm{pA}\left(10^{9} \mathrm{ion} / \mathrm{sec}\right.$ at IM exit, i.e. $2 \times 10^{6}$ ions per IM packet at $2 \mathrm{~ms}$ period of IM pulsing), before the space charge starts affecting IMS resolution. Accounting approximately $10 \%$ duty cycle of the OA in the EFP regime, and accounting multiple species in MS spectra, the IMS separation stage is expected to be then the limiting stage. If using a cylindrical coaxial IMS as proposed in $[39,42,134]$ it is expected to further increase the charge throughput of the IMS stage and to bring the overall throughput to approximately $10^{10}$ ion/sec in the IMS stage, corresponding to $10^{9} \mathrm{ion} / \mathrm{sec}$ at the MR-TOFMS detector. The expected dynamic range (minor component per total spectral content) is then expected up to $10^{8}$ per second.

The described IM-MR-TOFMS provides an opportunity for a rapid 3D-tag analysis (LC retention time, mobility and exact mass) of complex mixtures. The same apparatus may be switched to MS-MS mode, where the IMS serves as a parent ion separator. In-spite of moderate IMS resolution (30 to 50), the fragment spectra may be then extracted and correlated to precursor ions by time correlation in both time 
frames - chromatographic separation and mobility separation. The MS-MS regime may be used at discovery stage, where MS-MS spectra are used for reliable compound identification. Once the discovery is completed, the 3D-tag method is expected to be a very robust characterization method, identifying the target compounds at more sensitive measurements, since parent ion signal is not split between multiple fragments.

\section{D MS-MS IN Q-MR-TOFMS}

The method of Frequent Encoding Pulsing (EFP) in the MR-TOFMS with FFP provides an immediately available opportunity for improving the efficiency of $Q$ TOF tandems if using the method depicted in Figure 12 called 2D-MS-MS [45-47, 135]. A quadrupole filter is smoothly scanned with a wide open M1 window of 10 to $30 \mathrm{amu}$, this way reducing scan losses at parent ion separation stage compared to standard 1-2 amu Q1 window in Q-TOFMS tandems. Fast pulsing of the OA at mean $100 \mathrm{kHz}$ rate does allow to recover mass spectra and to track the time profile for every ion mass specie. This in turn is used to reconstruct fragment mass spectra, apparently assigned to parent masses at about 1 amu precision. Thus, the method provides approximately 10 to 30 fold gain of sensitivity without sacrificing the resolution of the parent ion selection.

Figure 13 shows experimentally obtained data with 2D-MS-MS method on a research grade Q-MRTOFMS instrument with ESI source operating in the infusion mode. The analyzed solution contains $100 \mathrm{uM}$ of reserpine and $0.1 \mathrm{uM}$ of Bovine Serum Albumin
(BSA) digest. Quadrupole filter was scanned once for 5 second scan time in a mass span from 300 to 1100 amu and with 20 amu wide window. Mass separated precursor ions were then fragmented at $30 \mathrm{eV}$ collisional energy. The OA was pulsed at $\sim 100 \mathrm{kHz}$ rate at the periodically repeated EFP pattern. Figure 13-A shows a total (TIC) signal at MR-TOFMS detector as a function of mean parent mass M1. The vertical scale is expanded 10-fold in order to see peaks of BSA peptides. The signal was EFP decoded to recover mass spectra for multiple wide time intervals (wider than time per M1 peak), and then the analytical ion current (AIC) plots were produced for each mass specie. The appearance of the fragment and precursor ions was correlated with the mean M1 mass to produce the 2D plot shown on the Figure 13-B. Vertical patterns of fragment spots correspond to the same M1 centroid which allows grouping the mass spectral peaks into fragment spectra, apparently assigned to precursor ions with $\Delta M 1=1$ amu accuracy, in spite of using wider (e.g. $20 \mathrm{amu}$ ) MS1 quadrupole window. A single 5 second analysis revealed 112 BSA peptides present at $0.1 \mathrm{uM}$ concentration in the sample. An example of minor peptide fragment spectra is shown in Figure 13C. The mass spectrum corresponds to overall 500 ions, however, because of $\sim p p m$ mass accuracy in MRTOFMS, the fragment spectrum still allows peptide identification. De-novo sequencing allows assignment of several peptide fragment peaks. The SIC of the same peptide is shown in Figure 13-E. The detected specie is minor and is at least 3 orders of magnitude smaller than the major reserpine specie shown in Figure 13-D.

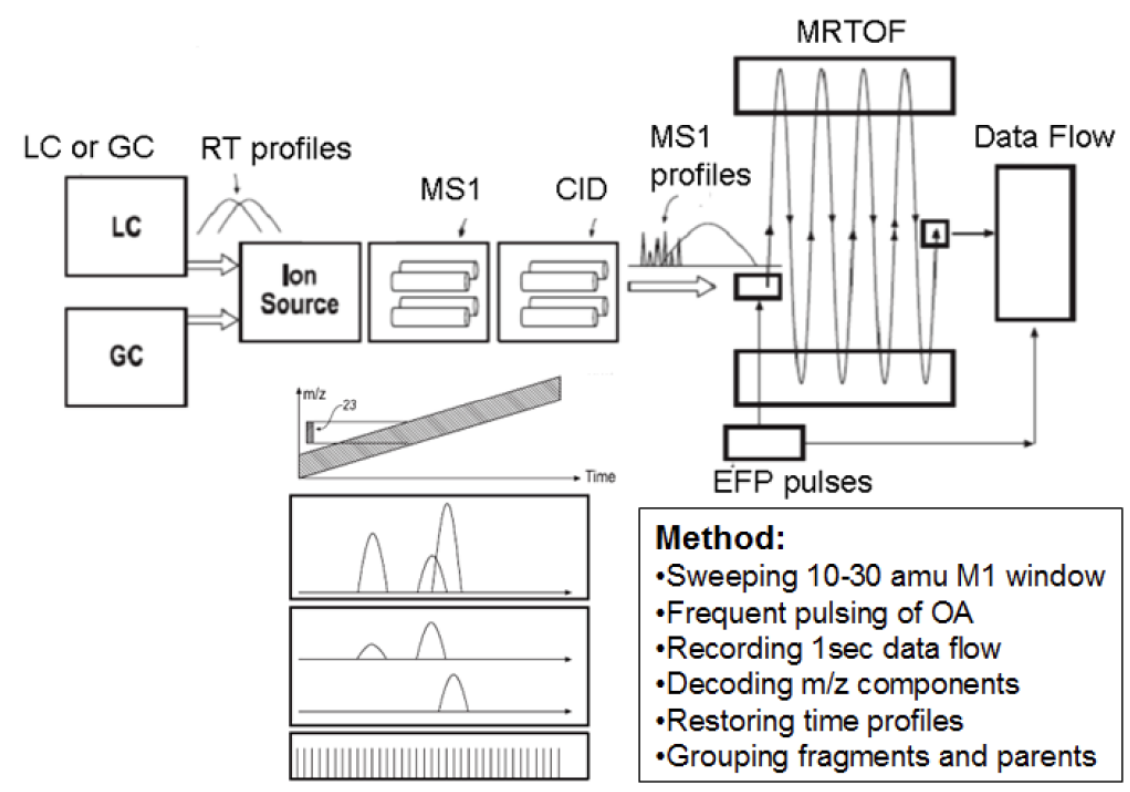

Figure 12: 
A: $\operatorname{TIC} \times 10$

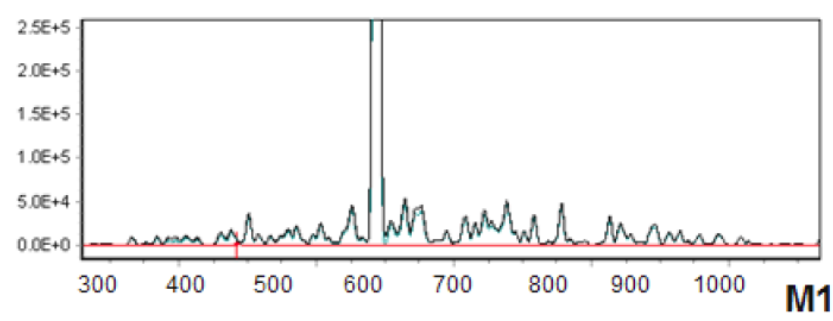

B: 2D-Map: M2 Vs M1

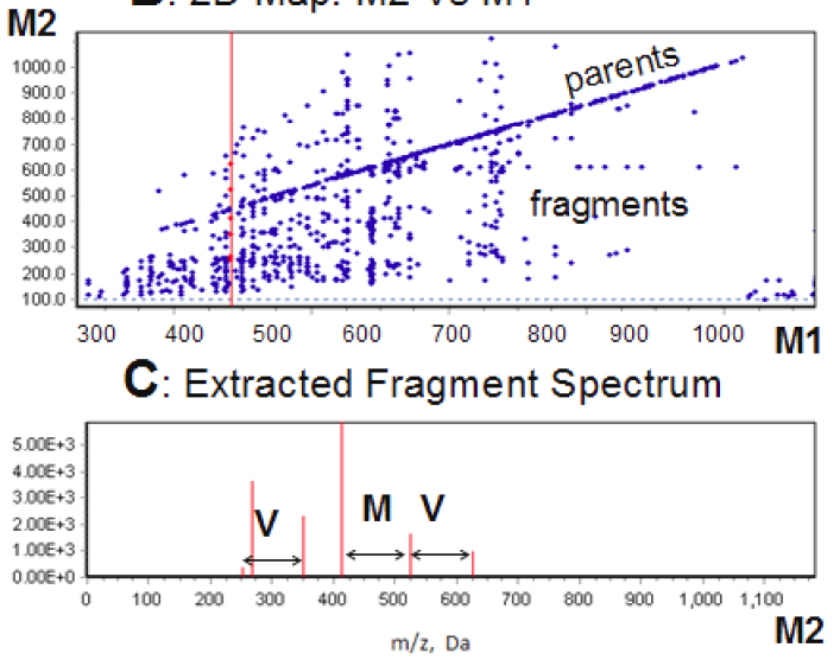

D: AIC for Reserpine

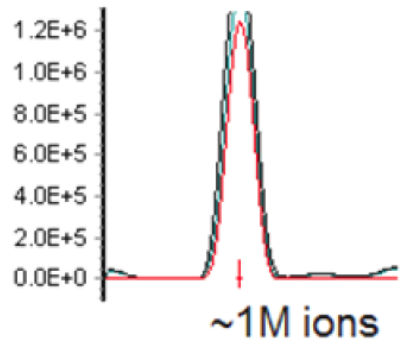

E: AIC for Peptide

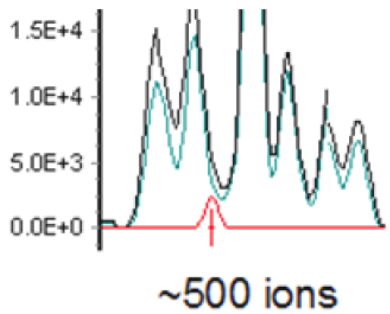

Figure 13:

The presented 2D-MS-MS method of analysis is data independent acquisition type, meaning that the same robust scan may be used independent of the sample composition. It provides MS-MS spectra for all parent species at 1 amu parent mass resolution. The measurement is accomplished in a single and fast quadrupole scan (0.3-3 sec), compatible with LC separation times. Using wide (from 10 to $30 \mathrm{amu}$ ) M1 mass window proportionally saves on parent scan duty cycle, comparing to stepping of individual $1 \mathrm{amu}$ windows, used in the typical way of MS-MS operation. The obtained MR-TOFMS fragment spectra are usually low populated, which allows reliable decoding of the EFP encoded spectra. High resolution of MR-TOFMS helps with interpreting spectra of minor species at minimal ion statistics.

The sensitivity and dynamic range of the method could be further enhanced if employing an ion trap upstream with sequential ion release and with a humongous space charge capacity of approximately $10^{9}$ ions [46]. The resolution of precursor ions selection may be improved with a synchronously scanning downstream quadrupole, still, the sensitivity gain would be proportional to resolution of the mass sequential ion release of the trap.

\section{TRAP ARRAY FOR PARENT SEPARATION}

The lossless parent scan for all-mass MS-MS is expected to be reached with a trap array, described in [46] and conceptually shown in Figure 14-A. To increase the charge throughput up to $10^{9} \mathrm{ion} / \mathrm{sec}$, the trap array is composed coaxially, employs multiple (30$50)$ linear traps being fairly long $(10-30 \mathrm{~cm})$. Further enhancement of the charge throughput is to be achieved by faster $(10 \mathrm{~ms})$ mass selective ejection at a moderate resolution (30 to 50 ). The mass selective ejection is arranged by opposing quadupolar DC and RF fields, which is less sensitive to space charge effects than resonant excitation methods.

Overall the apparatus (Figure 14-B) combines fast and lossless parent separation in the trap array with rapid mass spectral acquisition in MR-TOFMS, aided by frequent encoded pulsing of the orthogonal accelerator. Within $10 \mathrm{~ms}$ separation, each MS1 peak lasts for approximately 200 us, with time profile being detected during approximately twenty OA pulses.

Three operational methods are envisioned for the proposed apparatus. In one method, major spectral components are acquired in the MR-TOFMS with FFP, optionally with EFP. In the second, so-called dual MS 


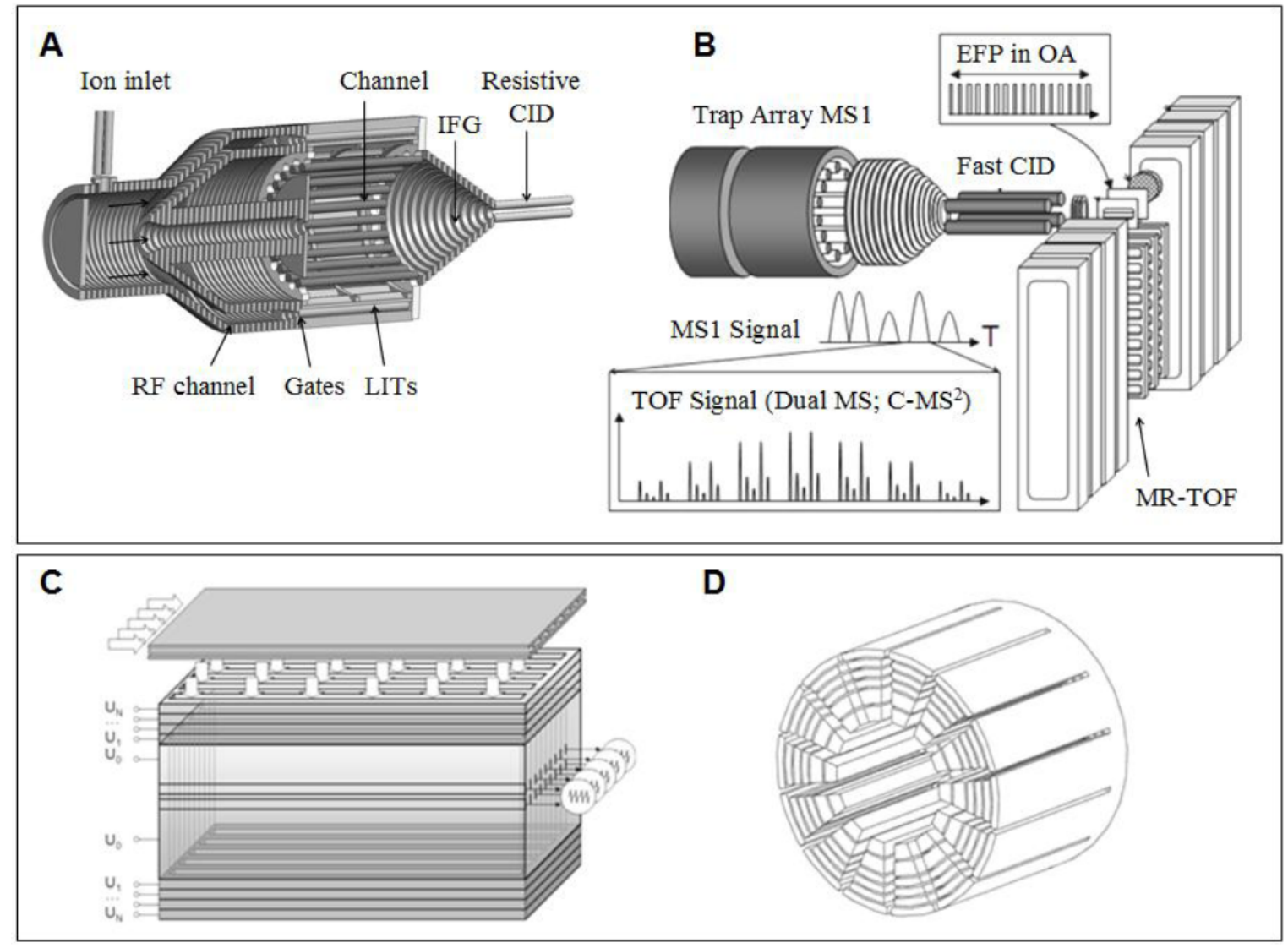

Figure 14:

method, the CID cell is setup for transmitting precursor ions without any significant fragmentation. As a result, EFP spectra are acquired for momentarily narrow mass range, this way fully avoiding spectral overlaps with EFP in OA. In the third method, comprehensive MS-MS method, mass separated precursor ions are subjected to fragmentation in the CID cell and then fragment spectra are analyzed in the MR-TOFMS. In spite of a relatively wide (10-20 amu) mass window for precursor ions, the window is smoothly scanned and time centroids are recovered from TOF signal profiles. Fragment spectra are then reconstructed and related to parent masses at about $1 \mathrm{amu}$ precisions, similarly to previously described 2D-MS-MS method. Contrary to 2D-MS-MS, the trap-array method is expected to completely avoid the parent ion losses.

In case of yet higher ion fluxes (potentially reaching $10^{10} \mathrm{ion} / \mathrm{sec}$ ), the resolution of the trap array is likely to fall to approximately $R=10$. Then it may be beneficial to use a downstream synchronized quadrupole at somewhat higher resolution from 50 to 100 . In this case, the trap array is still expected to enhance the parent selection sensitivity and the detection limit of the tandem MS by a factor of 10 .

\section{MR-TOF ARRAYS AND ELECTROSTATIC TRAPS}

An effective, though probably expensive, way of improving the MS throughput is to build multi-channel MS, employing multiple parallel TOF mass analyzers. The cost of building an MR-TOFMS array can be notably reduced with the method shown in Figure 14. The array of planar MR-TOF mass analyzers may be constructed by making a set of parallel slots in plane electrodes (Figure 14-C) or making radial slots in cylindrical electrodes (Figure 14-C). The analyzers then can share the same vacuum chamber and the same set of high voltage power supplies.

The MR-TOFMS array may be used to enhance the analyzer charge throughput when detecting large ion flows from a single bright ion source. In this case, it may be also convenient to multiplex the planar analyzer with rotation. Then electrode windows are to be made as radial slots. The pulsed converter may be diverting ion packets between analyzers, this way reducing space charge effects in the analyzers and also reducing the spectral overlaps if using the EFP method. Alternatively, high throughput analysis can be arranged with multiple chromatographic columns, ion source arrays, and multi-channel interfaces, feeding 
ions to individual MR-TOFMS channels. Source arrays and multi-channel interfaces may share common pumping system and common electronics to provide significant cost saving compared to a set of individual single channel mass spectrometers. Such system may be worth using for applications requiring high thoughput analyses, such in clinical applications, proteomics, etc.

\section{CONCLUSION}

Throughput of mass spectrometric analysis, expressed as the amount of information per analysis time (and which can be measured as product of main characteristics like analysis speed, sensitivity, and resolution) in the past two decades has been growing faster than the productivity of personal computers. Mass spectrometry has multiple resources to sustain such rapid growth for dealing with true complexity of real-life samples and to support the large-scale programs like proteome or fast and high volume clinical studies.

TOF mass spectrometry provides high speed analysis by its nature of parallel analysis. MR-TOF mass spectrometers dramatically enhance resolution and provide more spectral information at the enhanced mass accuracy, i.e. with better reliability. Frequent encoded pulsing improves MR-TOFMS sensitivity and opens opportunity for effective analysis by MS-MS and IMS-MS tandems. All-mass parallel separators, like high capacity IMS or trap arrays, are potentially suited to deliver lossless and fast scans to enhance the sensitivity and dynamic range, as well as providing robust strategies for data independent MS-MS acquisition. MR-TOFMS arrays are capable of delivering yet higher throughput at lower cost per single MS channel.

The development of novel instrumental principles and yet more efficient hardware is well supported by fast evolution of computers, data acquisition systems and TOF detectors. The supporting industry started paying more attention to the arising and further spreading TOFMS technology.

\section{REFERENCES}

[1] Cameron AE, Eggers DF. An ion "velocitron". Rev Sci Instrum 1948; 19: 605-7. https://doi.org/10.1063/1.1741336

[2] Wiley WC, McLaren IH. Time-of-flight mass spectrometer with improved resolution. Rev Sci Instrum 1955; 26: 1150-7. https://doi.org/10.1063/1.1715212

[3] Poschenrieder WP. Multiple-focusing time of flight mass spectrometers. Part II. TOFMS with equal energy acceleration. Int J Mass Spectrom lon Phys 1972; 9: 357-73. https://doi.org/10.1016/0020-7381(72)80020-2
[4] Alikhanov SG. A new pulse method of measuring the masses of ions. Sov Phys JETP. 1956; 4: 452-3.

[5] Mamyrin BA, inventor. Time-of-flight mass spectrometer. Russian Patent SU 198034. 1967 Sep.

[6] Frey R, Schlag EW, inventors. Time of flight mass spectrometer using an ion reflector. German Patent DE 3524536. 1987 Jan.

[7] Wollnik H, Grüner U, Li G. Flugzeit-Massenspektrometer mit gitterfreien Ionenspiegeln und Elektronenstoß-Ionenquellen. Ann Phys 1991; 503: 215-28. https://doi.org/10.1002/andp.19915030119

[8] Bletsos IV, Hercules DM, Greifendorf D, Benninghoven A. Time-of-flight secondary ion mass-spectrometry of nylons Detection of high mass fragments. Anal Chem 1985; 57: 2384-8.

https://doi.org/10.1021/ac00289a049

[9] Karas M, Bachmann D, Bahr U, Hillenkamp F. Matrixassisted ultraviolet laser desorption of non-volatile compounds. Int J Mass Spectrom Ion Proc 1987; 78: 53-68. https://doi.org/10.1016/0168-1176(87)87041-6

[10] Tanaka K, et al. Protein and polymer analyses up to $\mathrm{m} / \mathrm{z} 100$ 000 by laser ionization time-of-flight mass spectrometry. Rapid Comm Mass Spectrom 1988; 2: 151-3. https://doi.org/10.1002/rcm.1290020802

[11] O'Halloran GJ, Fluegge RA, Betts JF, Everett WL. Technical Documentary Report No. ASD-TDR-62-644, Parts I and II. The Bendix Corporation, Research Laboratory Division. Southfield, Ml; 1964.

[12] Dodonov AF, Chernushevich IV, et al. Method of massspectrometric analysis for time-of-flight of uninterrupted beam of ions. Russian Patent SU 1681340. 1987 Feb.

[13] Dresch T, Gulcicek E, Whitehouse C. Ion storage time-offlight mass spectrometer. United States Patent US 6020586. 2000 Feb.

[14] Loboda AV, Chernushevich I. Ion guide for mass spectrometer. Canadian Patent CA 2565455. 2005 Nov.

[15] Morris H.R, et al. High sensitivity collisionally-activated decomposition tandem mass spectrometry on a novel quadrupole/orthogonal-acceleration time-of-flight mass spectrometer. Rapid Comm Mass Spectrom 1996; 10: 88996.

https://doi.org/10.1002/(SICl)1097-

0231(19960610)10:8<889::AID-RCM615>3.0.CO;2-F

[16] Shevchenko A, et al. Rapid 'de novo' peptide sequencing by a combination of nanoelectrospray, isotopic labeling and a quadrupole/time-of-flight mass spectrometer. Rapid Comm Mass Spectrom 1997; 11: 1015-24.

https://doi.org/10.1002/(SICI)10970231(19970615)11:9<1015::AID-RCM958>3.0.CO;2-H

[17] Toyoda M, Okumura D, Ishihara M, Katakuse I. Multi-turn time-of-flight mass spectrometers with electrostatic sectors. J. Mass Spectrom 2003; 38: 1125-42.

https://doi.org/10.1002/jms.546

[18] Satoh $T$, Tsuno $H$, Iwanaga M, Kammei $Y$. The design and characteristic features of a new time-of-flight mass spectrometer with a spiral ion trajectory. J Am Soc Mass Spectrom 2005; 16: 1969-75. https://doi.org/10.1016/j.jasms.2005.08.005

[19] Wollnik H, Casares A. An energy-isochronous multi-pass time-of-flight mass spectrometer consisting of two coaxial electrostatic mirrors. Int J Mass Spectrom 2003; 227: 217-22. https://doi.org/10.1016/S1387-3806(03)00127-1

[20] Nazarenko LM, Sekunova LM, Yakushev EM. Time-of-Flight Mass Spectrometer with Multiple Reflections. Russsian Patent SU 1725289. 1992 Apr

[21] Verentchikov A, Campbell JM. Preparation of ion pulse for time-of-flight and tandem time-of-flight mass analysis. United States Patent US 6545268. 2003 Apr. 
[22] Verentchikov A. Time-nested mass analysis using a TOFTOF tandem mass spectrometer. Great Britain Patent GB 2390935. 2004 Jan.

[23] Verentchikov A. Tandem time-of-flight mass spectrometer and method of use. United States Patent US 7196324. 2007 Mar.

[24] Verentchikov A. Multi-reflecting time-of-flight mass spectrometer and a method of use. Great Britain Patent GB 2403063. 2004 Dec.

[25] Verentchikov A, Yavor M, Mitchell JC, Artaev V. Time of flight mass spectrometer employing a plurality of lenses focusing an ion beam in shift direction. Patent PCT WO 2005001878. 2005 Jan.

[26] Verentchikov A, Yavor M. Multi-reflecting time-of-flight mass spectrometer with orthogonal acceleration. Patent PCT WO 2007044696. 2007 Apr

[27] Verentchikov A, Yavor M. Multi-reflecting time-of-flight mass spectrometer with isochronous curved ion interface. Patent PCT WO 2006102430. 2006 Sep.

[28] Verentchikov A. Linear ion trap with an imbalanced radio frequency field. United States Patent US 7582864. 2009 Sep.

[29] Verentchikov A. Method and apparatus for ion manipulation using mesh in a radio frequency field. Patent PCT WO 2010014077. 2010 Feb.

[30] Verentchikov A, Yavor M. Quasi-planar multi-reflecting timeof-flight mass spectrometer. Patent PCT WO 2010008386. 2010 Jan.

[31] Verenchikov A, Khasin Y. Time-of-Flight mass spectrometer with accumulating electron impact ion source. Patent PCT WO 2012024468. 2012 Feb.

[32] Verenchikov A, Zamyatin A. Mass spectrometer with soft ionizing glow discharge and conditioner. Patent PCT WO 2012024570. Priority 2012 Feb.

[33] Verenchikov A. Electrostatic trap mass spectrometer. Great Britain Patent GB 2476964. 2011 Jul.

[34] Verenchikov A. Ion trap mass spectrometer. Patent PCT WO 2011086430. 2011 Jul.

[35] Verenchikov A. Open trap mass spectrometer. Great Britain Patent GB 2478300. 2011 Sep.

[36] Verenchikov A. Electrostatic mass spectrometer with encoded frequent pulses. Patent PCT WO 2011135477. 2011 Nov.

[37] Verenchikov A. Electrostatic trap mass spectrometer with improved ion injection. Patent PCT WO 2012092457. 2012 Jul.

[38] Verenchikov A, Yavor MI, Pomozov TV. Electrostatic ion mirrors. Patent PCT WO 2013063587. 2013 May.

[39] Verenchikov A. Ion mobility spectrometer. Patent PCT WO 2013067366. 2013 May.

[40] Verenchikov A. Electron impact source with fast response. Patent PCT WO 2013163530. 2013 Oct.

[41] Verenchikov AN, Makarov V. Tandem time-of-flight mass spectrometry with non-uniform sampling. Patent PCT WO 2013192161. 2013 Dec.

[42] Verenchikov A. Ion mobility spectrometer with high throughput. Patent PCT WO 2014021960. 2014 Feb.

[43] Verenchikov AN. Cylindrical multi-reflecting time-of-flight mass spectrometer. Patent PCT WO 2014074822. 2014 May.

[44] Verenchikov A, Yavor M. Multi-reflecting mass spectrometer. Patent PCT WO 2014142897. 2014 Sep.

[45] Verenchikov AN. Methods and system for tandem mass spectrometry. Patent PCT WO 2014152902. 2014 Sep.

[46] Verenchikov AN., Artaev V. Multi-reflecting mass spectrometer with high throughput. Patent PCT WO 2014176316. 2014 Oct.
[47] Verenchikov AN. Method of targeted mass spectrometric analysis. Patent PCT WO 2015152968. 2015 Oct.

[48] Verenchikov AN. Multi-reflecting time-of-flight mass spectrometer with an axial pulsed converter. Patent PCT WO 2015153630. 2015 Oct.

[49] Verenchikov AN, Vorobjev A. Right angle time-of-flight detectors with an extended life time. Patent PCT WO 2015153622. 2015 Oct.

[50] Verentchikov A, Yavor M, Pseudo plane multireflecting timeof-flight type mass spectrometer. Japanese Patent JP 2015038879. 2015 Feb.

[51] Verentchikov AN, Yavor MI. Dynamic well in electrostatic periodic systems. Abstratcs ASMS Conf. 2003.

[52] Verenchikov AN, Yavor MI. Stability of ion motion in periodic electrostatic fields. Nautchnoye priborostroeniye (Russian). 2004; 14(2): 46-58.

[53] Verentchikov A, Berdnikov A, Yavor M. Stable ion beam transport through periodic electrostatic structures: linear and non-linear effects. Phys Procedia. 2008; 1: 87-97.

https://doi.org/10.1016/j.phpro.2008.07.082

[54] Verentchikov AN, Hasin YI, Yavor MI. Multireflecting time-offlight mass analyzer retaining full mass range. Abstratcs ASMS Conf. 2004.

[55] Yavor MI, Verenchikov AN. Planar multi-reflection time-offlight mass analyzer working without restriction of the mass range. Nautchnoye priborostroeniye (Russian). 2004; 14(2): 38-45.

[56] Verenchikov AN. Concept of a multi-reflection mass spectrometer with a continuous ion source. Nautchnoye priborostroeniye (Russian). 2006; 16(3): 3-20.

[57] Verenchikov AN. Time-of-flight mass spectrometry of biopolymers based on planar multireflection analyzers. D. Sci. Thesis. St. Petersburg; 2006.

[58] Yavor MI, Verenchikov AN. Comparative analysis of multipass time-of-flight mass analyzers based on mirrors and sector fields. Nautchnoye priborostroeniye (Russian). 2006; 16(3): 21-9.

[59] Yavor M. Optics of charge particle analyzers. Advances in Imaging and Electron Physics, Vol. 157. Amsterdam: Acad. Press 2009.

[60] Khasin YI, Verenchikov AN, Gavrik MA, Yavor MI. First experimental studies of planar multireflecting TOF MS. Nautchnoye priborostroeniye (Russian). 2004; 14(2): 59-71.

[61] Verentchikov AN, Yavor MI, Hasin YI, Gavrik MA. Multireflecting time-of-flight mass analyzer for high-resolution mass spectrometers and parallel tandem analysis. Abstracts of International Desorption Conference: 2004: St. Petersburg 2004.

[62] Verentchikov AN, Yavor MI, Hasin YI, Gavrik MA Multireflection planar time-of-flight mass analyzer. II. High resolution mode. Technical Physics. 2005; 50(1): 82-6. https://doi.org/10.1134/1.1854828

[63] Verentchikov AN, Yavor MI, Hasin YI, Gavrik MA. Multireflecting TOF analyzer for high resolution MS and parallel MS-MS. Mass Spectrometry. 2005; 2: 11-20.

[64] Gavrik MA. Experimental study of properties of a planar multireflection time-of-flight mass analyzer. Cand. Sci. Thesis. St. Peresburg: 2005.

[65] Khasin YI, Verenchikov AN, Gavrik MA, Yavor MI. Planar time-of-flight analyzer in the mode of multiple reflections and high resolution. Nautchnoye priborostroeniye (Russian). 2005; 15(2): 112-20.

[66] Khasin YI, Gavrik MA, Yavor MI, et al. Planar multireflecting mass spectrometer with an Electrospray ion source. Nautchnoye priborostroeniye (Russian). 2006; 16(3): 30-9.

[67] Verentchikov AN, Hasin YI, Gavrik MA., et al. Multireflecting TOF MS with ESI ion source. Abstracts ICMS Conference, 2006: Prague 2006. 
[68] Lyutvinskij YI, Apatskaya MV, Kozlov BN, et al. Estimate of capacity of high resolution mass spectra at complex compound analysis. Nautchnoye priborostroeniye (Russian). 2006; 16(3): 122-31.

[69] Khasin YI, Gavrik MA, Kozlov BN, et al. Increasing sensitivity and mass accuracy of multireflection time-of-flight mass spectrometer with continuous ion sources. Nautchnoye priborostroeniye (Russian). 2006; 16(3): 11-8.

[70] Muradumov M, Hasin Y, Gavrik M, et al. Multireflecting Timeof-flight Mass Spectrometer with Electrospray Ion Source. Abstract of 8th European FTMS Conference 2007: Moscow 2007.

[71] Artaev V, Gardina M, Verentchikov A., et al. High Resolution TOF MS with Electrospray Ion Source. Abstr. ASMS Conference: 2007.

[72] Yavor M, Verentchikov A, Hasin $\mathrm{Y}$, et al. Planar multireflecting time-of-flight mass analyzer with a jig-saw ion path. Physics Procedia. 2008; 1: 391-400. https://doi.org/10.1016/j.phpro.2008.07.120

[73] Pomozov TV, Yavor MI. Gridless orthogonal accelerator for multireflection time-of-flight mass analyzers. Nautchnoye priborostroeniye (Russian). 2012; 22(1): 113-20. https://doi.org/10.1134/S106378421204024X

[74] Artaev V, Mason M, Patrick J, Verenchikov A. HighResolution time-of-Flight mass spectrometry via a folded flight path mass analyzer. Pittsburger Conference: 2012.

[75] Artaev V, Yavor M, Pomozov T, Verenchikov A. Advancements in multi reflecting high resolution TOF mass analyzers with folded flight path. Abstr. ASMS Conference: 2013.

[76] Verentchikov A, Khasin J, Muradymov M, et al. Ion velocity modulation for increasing duty cycle of time-of-flight mass spectrometers. Abstracts ICMS Conference 2009: Bremen 2009.

[77] Verenchikov AN, Muradzmov MZ, Gavrik MA, et al. Velocity modulation of an ion beam in an interface of a multireflection mass spectrometer with an orthogonal accelerator. Nautchnoye priborostroeniye (Russian). 2009; 19(4): 71-5.

[78] Pomozov TV, Yavor MI, Verentchikov AN. Reflectrons with ion orthogonal acceleration based on planar gridless mirrors. Technical Physics. 2012; 57(4). 550-5.

[79] Pomozov TV, Yavor Ml. On a possibility to improve characteristics of planar gridless ion mirrors. Nautchnoye priborostroeniye (Russian). 2011; 21(2): 90-7.

[80] Pomozov TV, Yavor MI, Verentchikov AN. Quasi-planar gridless ion mirrors in multireflection time-of-flight mass analyzers. Nautchnoye priborostroeniye (Russian). 2015; 25(3): 10-8. https://doi.org/10.18358/np-25-3-i1018

[81] Verenchikov A, Kolosov A, Kozlov B, Khasin Yu, Crude Oil Analysis with Multi-Reflecting TOF. Abstr. INN-MS Conference 2013.

[82] Allen L, Kolosov A, Artaev V, Verenchikov A. Development of a Soft Charge Transfer Ionization Source for Gas Chromatography used with a High Resolution Time of Flight Mass Spectrometer. Abstr. ASMS Conference 2013.

[83] Tikhonov G, Artaev V, Kozlov B, Siek K, Verenchikov A. Analysis of Crude Oil Samples on the Multi Reflecting High Resolution TOF at resolution over 160,000. Abstr. ASMS Conference 2014

[84] Verenchikov A, Kolosov A, Kozlov B, Khasin Yu. GC-TOF with Soft lonization and High Resolution for Analysis of Complex Mixtures. Abstr. EMEC Conference 2014.

[85] Kolosov A, Verenchikov A, Soft Ionization, NIST identification and Capabilities for Quantitative Analysis in Conditioned Glow Discharge Ion Source. Abstr. ASMS Conference 2015.
[86] Verenchikov AN, Kolosov AP. A Soft Ionization Method for Semivolatile Compounds. Anal. Chemistry. 2015; 70: 152732.

https://doi.org/10.1134/S1061934815130092

[87] Verenchikov AN. Parallel Ms-MS analysis in a time-of-flight tandem. Problem statement, method and device scheme. Nautchnoye priborostroeniye (Russian). 2004; 14(2): 24-37.

[88] Verenchikov A. Parallel MS-MS in TOF-TOF Tandems. Abstr. ASMS Conference 2004.

[89] Verentchikov AN, Yavor MI, Hasin YI, Gavrik MA. Multireflection planar time-of-flight mass analyzer. I. Analyzer for a parallel tandem spectrometer. Technical Physics. 2005; 50(1) 73-81. https://doi.org/10.1134/1.1854827

[90] Verenchikov AN, Kozlov BN, Yavor Ml, et al. Gas-filled linear quadrupole trap with axial ejection as a source for a multireflection time-of-flight mass spectrometer. Nautchnoye priborostroeniye (Russian). 2005; 15(2): 95-111.

[91] Yavor MI, Nikitina DV, Verenchikov AN, Kozlov BN. Ionoptical properties of a pulsed ion source based on a linear gas-filled trap. Nautchnoye priborostroeniye (Russian). 2005; 15(4): 27-41.

[92] Kozlov BN, Trufanov A, Muradumov MZ, et al. Linear lon Trap with Axial Ejection as a Source for a TOF MS. Abstr. ASMS Conference 2005.

[93] Kozlov BN, Trufanov AS, Yavor MI., et al. Multireflection time-of-flight mass spectrometer with an ion trap at the entrance. Nautchnoye priborostroeniye (Russian). 2006: 16(3): 40-8

[94] Verentchikov A, Kirillov S, Kozlov B, et al. Multi-Reflecting TOF MS with Isochronous Curved Inlet and Pulsed Ion Trap. Abstr. ICMS Conference: Bremen 2009.

[95] Artaev V, Kirillov S, Kozlov B, et al. High Resolution MultiReflecting TOFMS with Ion Trap Converter. Abstr. ASMS Conference 2014.

[96] Kozlov BN, Khasin YI, Kirillov SN, et al. Experimental study of space charge effects in multireflection time-of-flight analyzer. Nautchnoye priborostroeniye (Russian). 2006; 16(3): 49-58.

[97] Kozlov BN, Galeev G, Gavrik M, et al. Spase Charge Effects in Multireflecting Time-of-Flight Mass Spectrometer. Abstr. ASMS Conference 2006.

[98] Kirillov SN, Zamyatin AV, Alexeev DV, et al. Study of a cell for fast fragmentation and collisional cooling. Nautchnoye priborostroeniye (Russian). 2006; 16(3): 59-66.

[99] Yavor MI, Kirillov SN, Verenchikov AN. Interface for ion injection into a collision dissociation cell in a time-of-flight tandem with parallel analysis. Nautchnoye priborostroeniye (Russian). 2008; 18(2): 39-41.

[100] Kurnin IV, Yavor MI, Verenchikov AN, Zamyatin AV. Project of a collision dissociation cell for a tandem mass spectrometer with parallel analysis. Nautchnoye priborostroeniye (Russian). 2009; 19(4): 59-64.

[101] Kurnin IV, Yavor MI, Verenchikov AN. Use of a traveling field wave in a collision fragmentation cell for tandem mass spectrometers. Nautchnoye priborostroeniye (Russian). 2009: 19(4): 65-70.

[102] Vorobjev A, Kirillov S, Verenchikov A. Surface Induced Dissociation for Parallel TOF-TOF Tandem. Abstr. INN-MS Conference 2013.

[103] Vorobyev A, Trufanov A, Kirillov S, Verenchikov A. Characterisation of fragment ions produced in surface induced dissociation. Abstr. ASMS Conference 2014.

[104] Verenchikov A, Makarov V, Kozlov B, et al. Encoded Frequent Pulsing for Improving Duty Cycle of Multi Reflecting TOF MS. Abstr. INN-MS Conference 2013. 
[105] Willis P, Artaev V, Tikhonov G, et al. High Resolution MultiReflecting TOFMS with Multiplexing by Encoded Frequent Pulsing for increasing the duty cycle 10-100 times. Abstr. ASMS Conference 2015.

[106] Kozlov B, Makarov V, Kurnin I, Verenchikov A. Fast ion mobility spectrometry and High resolution TOF MS. Abstr. ASMS Conference 2014.

[107] Lobas AA, Verenchikov AN, Goloborodko AA, et al. Combination of Edman degradation of peptides with liquid chromatography/mass spectrometry workflow for peptide identification in bottom-up proteomics. Rapid Comm Mass Spectrom 2013; 27: 391-400. https://doi.org/10.1002/rcm.6462

[108] Lobas AA, Ivanov MV, Levitsky LI, et al. Applicability of partial Edman degradation for MS/MS-free protein identifications in shotgun proteomics. Abstr. ASMS Conference 2014

[109] Verenchikov AA. Path from Multi-Reflecting TOF to electrostatic traps. Abstr. ETMS Conference 2012.

[110] Verenchikov A, Artaev S, Yavor M, Makarov V. Non orbital electrostatic traps and MR-TOF. Abstr. IMSC Conference 2014.

[111] Yavor MI, Plaß WR, Dickel T, et al. Ion-optical design of a high performance multiple-reflection time-of-flight mass spectrometer and isobar separator. Int $\mathrm{J}$ Mass Spectrom. 2015: 381-382: 1-9 https://doi.org/10.1016/j.ijms.2015.01.002

[112] Dickel T, Plass WR, Becker A, et al. A high-performance multiple-reflection time-of-flight mass spectrometer and isobar separator for the research with exotic nuclei. Nucl Instrum Meth Phys Res A. 2015: 777: 172-88. https://doi.org/10.1016/j.nima.2014.12.094

[113] Klitzke CF, et al. Petroleomics by Ultrahigh-Resolution Timeof-Flight mass spectrometry. Energy Fuels. 2012; 26: 578794.

https://doi.org/10.1021/ef300961c

[114] Lebedev AT, et al. The benefits of high resolution mass spectrometry in environmental analysis. Analyst. 2013; 138: 6946-53.

https://doi.org/10.1039/c3an01237a

[115] Tolstikov $V$, et al. Metabolomics analysis of metabolic effects of nicotinamide phosphoribosyltransferase (NAMPT) inhibition on human cancer cells. PLoS ONE. 2014; 9: e114019+.

https://doi.org/10.1371/journal.pone.0114019

[116] Tranchida PQ., et al. Flow-Modulated comprehensive TwoDimensional gas chromatography combined with a HighResolution Time-of-Flight mass spectrometer: A Proof-ofPrinciple study. Anal Chem. 2015; 87: 2925-30. https://doi.org/10.1021/ac5044175

[117] Xie X, et al. Primordial soup was edible: abiotically produced Miller-Urey mixture supports bacterial growth. Sci Rep. 2015; 5: 14338

https://doi.org/10.1038/srep14338
[118] Reinhold BB, Verentchikov A. Multiple Stage Mass Spectrometer. United States Patent US 6483109. 2002 Nov.

[119] Verenchikov AN. High sensitive tandem mass spectrometer. Internal Invention Disclosure at Applied Biosystems Inc. 1999 Oct.

[120] Wang H, Kerry DN. Two-dimensional tandem mass spectrometry. United States Patent US 6770871. 2004 Aug.

[121] Makarov AA, Syka JEP. Obtaining tandem mass spectrometry data for multiple precursor ions in an ion population. United States Patent US 7157698. 2004 Nov.

[122] Myung S, Ethan R, Badman ER, Lee YJ, Clemmer DE. Structural Transitions of Electrosprayed Ubiquitin lons Stored in an Ion Trap over $\sim 10 \mathrm{~ms}$ to $30 \mathrm{~s}$. J Phys Chem A. 2002; 106: $9976-82$.

https://doi.org/10.1021/jp0206368

[123] Myung S, Lee YJ, Moon MH, et al. Development of highsensitivity ion trap ion mobility spectrometry time-of-flight techniques: a high-throughput nano-LC-IMS-TOF separation of peptides arising from a Drosophila protein extract. Anal Chem. 2003; 75: 5137-45. https://doi.org/10.1021/ac030107f

[124] Franzen J. High resolution method for using time-of-flight mass spectrometers with orthogonal ion injection. United States Patent US 6861645. 2004 Aug.

[125] Kenny DJ, Widlgoose JL. An orthogonal acceleration time-offlight mass spectrometer. Great Britain Patent GB 2445679. 2008 Jul.

[126] Knorr FJ. Fourier transform time-of-flight mass spectrometer United states Patent US 4707602. 1987 Nov.

[127] Brock A, Rodriguez N, Zare RN. Time-of-flight mass spectrometer and ion analysis. United States Patent US 6300626. 2001 Oct.

[128] Belov M, Fancher C, Foley P. Multiplexed orthogonal time-offlight mass spectrometer. United States Patent US 6900431. 2004 Sep.

[129] Belov ME. Dynamic multiplexed analysis using ion mobility spectrometer. United States Patent US 7718957. 2009 Dec.

[130] Belov ME, Smith RD. Improved method of multiplexed analysis using ion mobility spectrometer. United States Patent US 7541576. 2008 Aug.

[131] Hoyes JB. An ion mobility spectrometer coupled to a scanning mass filter and fragmentation cell. Great Britain Patent GB 2390478. 2004 Jan.

[132] Bateman RH, Hoyes JB. Method and apparatus for mass spectrometry. United States Patent US 6586727. 2001 Dec .

[133] Bateman RH, Hoyes JB. Method and apparatus for mass spectrometry. United States Patent US 6717130. 2002 May.

[134] Green MR, Langridge DJ. Annular ion guide. United States Patent US 2015048246. 2015 Feb.

[135] Giles K, Green RM, Richardson K, Wildgoose JL. Encoding of precursor ion beam to aid product ion assignment. United States Patent US 2014346341. 2014 Nov.

Received on 08-11-2016

Accepted on 15-12-2016

Published on 02-03-2017

\section{DOI: https://doi.org/10.6000/1929-5030.2017.06.01.1}

(C) 2016 Verenchikov et al.; Licensee Lifescience Global.

This is an open access article licensed under the terms of the Creative Commons Attribution Non-Commercial License (http://creativecommons.org/licenses/by-nc/3.0/) which permits unrestricted, non-commercial use, distribution and reproduction in any medium, provided the work is properly cited. 